\title{
Primary hyperparathyroidism: review and recommendations on evaluation, diagnosis, and management. A Canadian and international consensus
}

\author{
A. A. Khan ${ }^{1,2}$ • D. A. Hanley ${ }^{3} \cdot$ R. Rizzoli $^{4}$ - J. Bollerslev ${ }^{5}$. J.E.M Young ${ }^{1}$ • \\ L. Rejnmark ${ }^{6}$ • R. Thakker ${ }^{7}$ • P. D'Amour ${ }^{8}$ - T. Paul ${ }^{9}$ - S. Van Uum ${ }^{9}$ • \\ M. Zakaria Shrayyef ${ }^{10}$ - D. Goltzman ${ }^{11}$ - S. Kaiser ${ }^{12}$ - N. E. Cusano ${ }^{13}$ • R. Bouillon ${ }^{14}$ $^{1}$ \\ L. Mosekilde ${ }^{15}$ - A. W. Kung ${ }^{16}$ • S. D. Rao ${ }^{17}$ - S. K. Bhadada ${ }^{18}$ • B. L. Clarke ${ }^{19}$ • J. Liu ${ }^{20}$ • $^{2}$

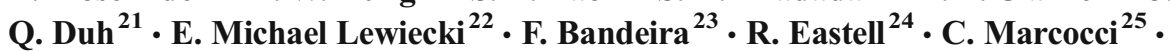 \\ S. J. Silverberg ${ }^{26}$ • R. Udelsman ${ }^{27}$ • K. Shawn Davison ${ }^{28}$ • J. T. Potts Jr $^{29}$ • $^{2}$ \\ M. L. Brandi ${ }^{30}$ • J. P. Bilezikian ${ }^{26}$
}

Received: 10 February 2016 / Accepted: 20 July 2016 / Published online: 9 September 2016

(C) The Author(s) 2016. This article is published with open access at Springerlink.com

\begin{abstract}
The purpose of this review is to assess the most recent evidence in the management of primary hyperparathyroidism (PHPT) and provide updated recommendations for its evaluation, diagnosis and treatment. A Medline search of "Hyperparathyroidism. Primary" was conducted and the literature with the highest levels of evidence were reviewed and used to formulate
\end{abstract}

\section{A. A. Khan}

Aliya@momaster.ca

\section{McMaster University, Hamilton, Canada}

2 Bone Research and Education Center, 223-3075 Hospital Gate, Oakville, ON, Canada

3 University of Calgary, Calgary, Canada

4 Division of Bone Diseases, Geneva University Hospitals and Faculty of Medicine, Geneva, Switzerland

5 University of Oslo, Oslo, Norway

6 Department of Endocrinology and Internal Medicine, Aarhus University Hospital, Aarhus, Denmark

7 University of Oxford, Oxford, UK

8 CHUM, Montreal, Canada

9 Western University, London, ON, Canada

10

Division of Endocrinology, University of Toronto, Mississauga, ON, Canada

11 McGill University, Montreal, Canada

12 Dalhousie University, Halifax, Canada

13 Columbia University College of Physicians and Surgeons, New York, NY, USA recommendations. PHPT is a common endocrine disorder usually discovered by routine biochemical screening. PHPT is defined as hypercalcemia with increased or inappropriately normal plasma parathyroid hormone (PTH). It is most commonly seen after the age of 50 years, with women predominating by three to fourfold. In countries with routine multichannel screening, PHPT is

$14 \mathrm{KU}$, Leuven, Belgium

15 University of Aarhus, Aarhus, Denmark

16 University of Hong Kong, Hong Kong, China

17 Henry Ford Hospital, Detroit, MI, USA

18 Postgraduate Institute of Medical Education and Research, Chandigarth, India

19 Mayo Clinic, Rochester, MN, USA

20 Rui-Jin Hospital, Shanghai Jiao-Tong University School of Medicine, Shanghai, China

21 University of California, San Francisco, CA, USA

22 New Mexico Clinical Research and Osteoporosis Center, University of New Mexico School of Medicine, Albuquerque, NM, USA

23 Division of Endocrinology, Diabetes and Metabolic Bone Diseases, Agamenon Magalhaes Hospital, Brazilian Ministry of Health, University of Pernambuco Medical School, Recife, Brazil

24 Department of Human Metabolism, University of Sheffield, Sheffield, UK

25 Department for Clinical and Experimental Medicine, University of Pisa, Endocrine Unit 2, University Hospital of Pisa, Pisa, Italy

26 Division of Endocrinology, Columbia University College of Physicians and Surgeons, New York, NY, USA 
identified earlier and may be asymptomatic. Where biochemical testing is not routine, PHPT is more likely to present with skeletal complications, or nephrolithiasis. Parathyroidectomy (PTx) is indicated for those with symptomatic disease. For asymptomatic patients, recent guidelines have recommended criteria for surgery, however PTx can also be considered in those who do not meet criteria, and prefer surgery. Non-surgical therapies are available when surgery is not appropriate. This review presents the current state of the art in the diagnosis and management of PHPT and updates the Canadian Position paper on PHPT. An overview of the impact of PHPT on the skeleton and other target organs is presented with international consensus. Differences in the international presentation of this condition are also summarized.

Keywords Diagnosis · Management · Osteoporosis · Primary hyperparathyroidism $\cdot$ Surgery $\cdot$ Treatment

\section{Introduction and methods}

Primary hyperparathyroidism (PHPT) has evolved in its clinical presentation over the past 40 years and is now usually diagnosed at an asymptomatic stage [1]. Parathyroidectomy (PTx) is the only curative approach to this disease. It is indicated in those with symptomatic PHPT and advised for those who meet the surgical guideline criteria. It is also a reasonable option among those who request surgery, even if they do not meet surgical guidelines and have no contraindications [2]. Advances in medical management have also taken place over the past decade. For individuals in whom surgery is not possible or desirable, valuable approaches for skeletal protection and lowering of serum calcium have become available [3].

In this Canadian position paper, we update our previously published guidelines on PHPT with international consensus [4]. Canadian participation was invited at the Fourth International Workshop held in Florence Italy 2013. Canadian representatives met international colleagues in Florence and developed key questions addressing evaluation, imaging, diagnosis, and management of PHPT. Canadian representatives collaborated with international colleagues and formalized evidence-based recommendations to each of the key questions listed. A detailed section on parathyroid imaging was developed as this was highlighted as a need by Canadian endocrinologists. This position paper was supported and endorsed by Canadian Endocrine Update, McMaster University, and Western University. We summarize recent

\footnotetext{
27 Department of Surgery, Yale University School of Medicine, New Haven, CT, USA

28 University of Victoria, Victoria, BC, Canada

29 Massachusetts General Hospital, Harvard University, Boston, MA, USA

30 University of Florence, Florence, Italy
}

evidence and provide recommendations pertaining to the evaluation, diagnosis, presentation, and management of PHPT.

We searched Medline from April 15, 2010, to June 14, 2016, using the MeSH search term "Hyperparathyroidism, Primary" [Mesh], excluding reviews, letters, and editorials and specifying only English language papers dealing with humans. Of the 728 citations that were obtained, we included those articles with the highest levels of evidence available, as well as those reflective of international consensus. Papers identified by content experts (senior authors AK, DH) as being essential for enhanced understanding, but published before the search period, were also included as decided by expert opinion. Not all articles are included in this review due to the limit on the number of references; however, articles with the highest level of evidence are included as well as key consensus papers.

\section{What is the natural history of PHPT with or without parathyroid surgery?}

Five prospective studies, four of which were randomized control trials and one long-term observational study, evaluated the effect of PTx on the skeletal and renal manifestations of PHPT [5-9]. PTx is associated with significant improvements in bone mineral density (BMD). Without surgical intervention, BMD is stable or decreases with long-term follow-up [5-8]. Data from a 5-year randomized controlled study demonstrated a lower rate of vertebral fracture post-PTx ( 0 vs 5 fractures) in comparison to no surgery [9]. The difference in the frequency of the fractures between observation and PTx was not statistically significant $(p=0.058)$; however, it is suggestive of skeletal protection with PTx. Observation may also be safe as the overall frequency of fracture was low. The individuals with fracture had similar age, BMD, and laboratory profile to the remaining study group subjects suggesting that BMD may not be as predictive of future fracture risk in PHPT patients as compared to patients without PHPT. The longest natural history study with 15 years of follow-up enrolled 121 patients, of whom $85 \%$ were asymptomatic, $51 \%$ had PTx during follow-up, and $49 \%$ were followed without surgery [8]. BMD was stable during the first 8 years in those who did not receive PTx and subsequently declined at the femoral neck and distal onethird radius (mean losses of 10 and $35 \%$, respectively). This study has several limitations including the fact that only six patients with long-term follow-up demonstrated progressive decreases in BMD between year 10 and 15 . However, the eventual decline in BMD following a long period of stability suggests that long-term monitoring is essential in those who do not undergo PTx.

Renal stone risk declines significantly following PTx, with a reduction in the risk of recurrent renal stones, although the risk remains higher than the risk in the general population [10]. Following surgical cure by PTx, the relative risk of renal stones in comparison to eucalcemic controls is still increased among patients with stones prior to PTx (incidence rate ratio 
[IRR] 75.9; $95 \% \mathrm{CI}, 45.8$ to 125.5$)$ as well as in patients without a history of renal stones (IRR 2.8; $95 \% \mathrm{CI}, 1.5$ to 5.5) [11]. Some patients may continue to have higher urine calcium and lower serum phosphate levels compared with healthy controls after successful PTx, suggesting a persistent or additional mineral disorder [12]. Successful PTx also appears to prevent decline in renal function in those with chronic kidney disease as observed in a recent retrospective crosssectional study in 109 consecutive PHPT patients evaluated before and after PTx [13]. Presurgical renal function appears to be a relevant predictor of renal function after PTx [13].

\section{Presentation}

Classically, PHPT targets the kidney and the skeleton. The extent to which a patient will present with overt involvement of these target organs varies depending on the availability of multichannel screening in a given country. An overview of the international presentation of PHPT is summarized below.

\section{Skeletal involvement}

Radiographic signs of the PHPT include a salt-and-pepper pattern skull demineralization, distal clavicle tapering, subperiosteal bone resorption, cysts, and brown tumors. Together, these features are described as osteitis fibrosa cystica and are rarely seen in developed countries where more subtle forms of skeletal involvement are observed. Low BMD is especially prevalent at sites with high proportions of cortical bone, such as the distal one-third radius [14]. The lumbar spine BMD appears to be relatively well preserved in PHPT [15].

Fracture data from cohort studies suggest an increased risk of all fractures including vertebral fractures, and this risk of fracture appears to decrease following PTx $[16,17]$. The lumbar spine BMD may not be a useful predictor of fracture risk in PHPT. Accordingly, BMD should be measured at the onethird radius site in all individuals with PHPT [18].

Epidemiological studies of patients with PHPT report increases in fracture risk at all skeletal sites [17, 19]. Further, high-resolution peripheral quantitative tomography has shown that both trabecular and cortical bone compartments are affected in patients with PHPT $[20,21]$. HRpQCT indices correlate with fracture prevalence in PHPT, and this correlation is independent of BMD as measured by dual-energy X-ray absorptiometry (DXA) [20]. Post-PTx improvement in microarchitecture, cortical thickness, bone density, and estimated bone strength is seen [22]. The trabecular bone score (TBS) analysis evaluates bone microarchitecture from the lumbar spine DXA image and measures bone strength [23]. TBS predicts fracture risk independent of BMD [23]. TBS analysis in PHPT is consistent with deteriorated trabecular microstructure and increased fracture risk [24].
TBS is lower in individuals with PHPT in comparison to eucalcemic controls [25] and improves following parathyroidectomy [26]. In PHPT, the combination of TBS and BMD may provide a more accurate assessment of bone strength in the central skeleton than the LS BMD as measured by DXA alone.

\section{Renal involvement}

Renal stones are a major complication of PHPT [1]. In Western countries, the prevalence of clinically overt stone disease has decreased from approximately $80 \%$ of patients in earlier series to 7-20\% presently [1]. However, in systematically screened patients the diagnostic prevalence may be higher (25-55 \%) [27]. Generally, patients with PHPT who develop renal stones are younger and more often male [1].

Hypercalciuria is a known risk factor for renal stones [10]. Hypercalciuria likely contributes to an increased risk of renal stones.

The relationship between nephrolithiasis and PHPT is not well understood at this time. It appears that 24-h urine calcium is higher in stone formers with PHPT in comparison to nonstone formers with PHPT [28-30]. However, this has not been observed consistently [31-33] and requires further prospective evaluation. Following PTX, the risk of renal stones is lowered and the presence of marked hypercalciuria is therefore included as a guideline for surgery.

The pathogenesis of increased renal stone formation in PHPT has not yet been fully elucidated. Hypercalciuria by itself does not fully explain the increased risk, and only limited data is currently available on the potential impact of other biochemical abnormalities, such as renal acidification abnormalities on the risk of stones in PHPT [10, 34]. There is no reliable data available on the feasibility of performing metabolic evaluation of stone formers with PHPT, but due to a persistent increased risk after surgical cure of PHPT, it is reasonable to consider screening for other common causes for kidney stones. This includes measurements of serum uric acid and urinary $\mathrm{pH}$ as well as assessment of urine volume and the presence of hyperuricosuria, hypomagnesiuria, hyperoxaluria, hypocitraturia, or cystinuria [35]. The effect of renal function on PTH secretion has been extensively evaluated [36, 37]. Reductions in estimated glomerular filtration rate (eGFR) are inversely correlated with serum intact PTH [38]. Decreases in renal function (GFR $<70$ vs $>70 \mathrm{~mL} / \mathrm{min}$ ) have been associated with more severe impact on bone strength with greater reductions in BMD particularly at cortical skeletal sites in individuals with PHPT [39]. These data support the recommendations for parathyroidectomy in those with GFR of $<60 \mathrm{~mL} / \mathrm{min}$. Successful PTx appears to prevent decline in renal function in those with chronic kidney disease (eGFR $<60 \mathrm{~mL} / \mathrm{min}$ ) as observed in a recent retrospective crosssectional study in 109 consecutive PHPT patients evaluated 
before and after PTx [13]. These data also support the recommendation for PTx in those with an eGFR of $<60 \mathrm{~mL} / \mathrm{min}$.

\section{Non-classical manifestations of PHPT}

While PHPT has been associated with neurocognitive changes and depression [1], these cognitive changes have not consistently improved following PTx [40].

Severe PHPT characterized by higher serum calcium levels (calcium $\geq 11.2 \mathrm{mg} / \mathrm{dl}$ ) has been associated with an increased risk of cardiovascular mortality [41]. PHPT appears to be associated with an increased risk of developing left ventricular hypertrophy, impaired diastolic filling, and myocardial calcification [42-44]. Yu et al. [45] observed in a retrospective population-based study in Tayside, Scotland, that mild PHPT (calcium $<2.9 \mathrm{mmol} / \mathrm{L}$ ) also was associated with an increased risk of cardiovascular and cerebrovascular disease in comparison to the age- and sex-matched general population and that this increase in mortality was similar to those with symptomatic or severe disease.

Further, Yu et al. [46] have also recently observed that baseline calcium levels were not significantly related to fatal cardiovascular disease or non-fatal cardiovascular disease in PHPT. However, serum PTH rather than serum calcium appeared to be associated with an increased risk of fatal and nonfatal cardiovascular disease. In this study, vitamin D levels were not completed and vitamin D inadequacy may have contributed to elevations in PTH and also impacted mortality.

Studies to date have not all shown improvements in cardiovascular disease following PTx, and this may depend on the presence and severity of preexisting cardiovascular disease [47-49].

A clinical evaluation of cardiovascular risk for the purpose of evaluating perioperative risk of cardiovascular complications may be undertaken. However, currently there is insufficient evidence to recommend proceeding with PTx in order to lower the risk of cardiovascular events. Large randomized controlled trial data will need to be completed in order to determine if PTx lowers cardiovascular and all-cause mortality.

\section{International presentations of PHPT (Table 1)}

In USA, Canada, and Europe, asymptomatic disease has been the predominant presenting clinical phenotype over the past 40 years [53]. Nephrolithiasis prevalence has decreased and overt skeletal manifestations are uncommon. Normocalcemic hyperparathyroidism (NPHPT) may be identified during the evaluation of patients with low BMD [63].

NPHPT may progress to hypercalcemic PHPT. Currently, most of the data regarding NPHPT has been obtained from evaluation of patients referred for assessment of complications including osteoporosis, fracture, and nephrolithiasis [64-68].
Very limited prospective data is available on the natural history of NPHPT.

In Latin America, large case series as well as epidemiologic studies have reported up to $44 \%$ of patients with renal stones [59]. In the early 2000s in China, serum calcium levels were higher at presentation than seen in the Western world and $60 \%$ had radiological alterations. The prevalence of asymptomatic PHPT has since increased in China $[60,61]$. In contrast to China, the clinical presentation of PHPT in India does not appear to have changed over the past 50 years [62]. The predominant presenting features continue to be skeletal involvement and renal complications as well as symptoms of hypercalcemia with less than $5 \%$ asymptomatic presentation [62].

This global survey of PHPT documents substantial differences in the presentation of the condition in the various regions of the world with varying prevalence of target organ involvement.

\section{Diagnosis and imaging}

\section{How is primary hyperparathyroidism diagnosed today?}

The combination of hypercalcemia and an elevated or inappropriately normal parathyroid hormone $(\mathrm{PTH})$ level makes PHPT the most likely diagnosis [69] (please see Fig. 1, normal sigmoidal relationship between calcium and PTH). Measured total serum calcium should be adjusted for albumin [69]. If the corrected serum calcium is normal and PTH is elevated, serum ionized calcium should be measured, as PHPT can present with an elevated ionized calcium despite a normal albuminadjusted serum calcium [69]. Ionized calcium measurements are reliable if samples are collected under anaerobic conditions maintaining the original $\mathrm{pH}$ of the specimen, as acidosis is associated with an increase in ionized calcium. The specimen should be stored or centrifuged at $4{ }^{\circ} \mathrm{C}$ for up to $2 \mathrm{~h}$, as longer time periods can result in changes in $\mathrm{Ca}^{2+}$ concentration. The ionized calcium result can be corrected mathematically for changes in $\mathrm{pH}$ due to exposure of the specimen to air; however, this will only be an approximation of the true anaerobic ionized calcium [70]. The differential diagnosis of hypercalcemia includes conditions which mimic PHPT, including familial hypocalciuric hypercalcemia (FHH) and certain medication use, such as hydrochlorothiazide or lithium [69]. Both second- and third-generation PTH assays are of value in diagnosing PHPT and provide comparable results [71].

NPHPT has been increasingly recognized over the past decade [1], typically following PTH measurement for assessment for secondary osteoporosis. An elevated serum PTH in the presence of consistently normal albumin-adjusted calcium and ionized calcium, normal serum 25-hydroxyvitamin D $(25 \mathrm{OHD}>20 \mathrm{ng} / \mathrm{mL}$ or $50 \mathrm{nmol} / \mathrm{L}$ ), and well-maintained renal 
Table 1 International presentation of PHPT.

\begin{tabular}{|c|c|c|c|c|}
\hline & Overall Incidence/Prevalence & $\begin{array}{l}\text { Incidence/Prevalence } \\
\text { In Women }\end{array}$ & $\begin{array}{l}\text { Incidence/Prevalence } \\
\text { In Men }\end{array}$ & Comments \\
\hline $\begin{array}{l}\text { United States } \\
\text { [50-52] } \\
\text { Canada [53] }\end{array}$ & $\begin{array}{l}0.86 \% \text { General Population } \\
0.4-3.1 \%\end{array}$ & $\begin{array}{l}34-120 \text { (Mean: } 66) * \\
196 \text { (70-79 Yrs) } \\
3.3 \%\end{array}$ & $\begin{array}{l}13-36 \text { (Mean: } 25) * \\
95 \text { (70-79 Yrs) } \\
1.4 \%\end{array}$ & $\begin{array}{l}\text { Higher incidence in Blacks than } \\
\text { Caucasians than Asians } \\
\text { Predominant presentation: } \\
\text { asymptomatic disease } \\
74 \% \text { postmenopausal }\end{array}$ \\
\hline Europe $[54,55,56]$ & $\begin{array}{l}1.07 \% \\
9.95 * \\
\text { Hospitalisation for } \\
\text { PHPT: } 8.3 / 100^{\prime} 000\end{array}$ & $1.6 \%$ & $0.3 \%$ & $\begin{array}{l}\text { Increase of prevalence over time } \\
\text { Surgery proposed: } 32 \% \text { (Italy), } \\
66 \% \text { (Spain), 64\% (France), } \\
53 \% \text { (UK) }\end{array}$ \\
\hline $\begin{array}{l}\text { Latin America } \\
\text { [57-59] }\end{array}$ & $0.78 \%$ & & & $\begin{array}{l}\text { Asymptomatic disease: } 47-82 \% \\
\quad(18-44 \% \text { kidney stones })(6.1 \% \\
\text { osteitis fibrosa cystica) } \\
90 \% \text { postmenopausal }\end{array}$ \\
\hline $\begin{array}{c}\text { Asia - China } \\
{[60,61]}\end{array}$ & & & & $\begin{array}{l}60 \% \text { with radiological signs, } 40 \% \\
\text { kidney stones } \\
\text { Asymptomatic disease } 20 \% \text { before } \\
2006 \text { to } 50 \% \text { in } 2007-2010\end{array}$ \\
\hline $\begin{array}{l}\text { Asia - India } \\
{[2,62]}\end{array}$ & & & & $\begin{array}{l}\text { Asymptomatic disease: }<5 \% \\
\text { Predominant presenting features: skeletal } \\
\text { and renal complications, as well as } \\
\text { anemia. } \\
\text { Resistance to erythropoietin. Improvement } \\
\text { of anemia after PTx. } \\
\text { Higher prevalence of GI tract symptoms } \\
\text { than in the rest of the world. } \\
\text { PTx in }>80-90 \% \text { of PHPT }\end{array}$ \\
\hline
\end{tabular}

*: per 100,000 person-years

function (eGFR $>60 \mathrm{~mL} / \mathrm{min} / 1.73 \mathrm{~m}^{2}$ ) supports this diagnosis [69]. Other secondary causes for an elevated PTH should be excluded, such as primary hypercalciuria, malabsorption syndromes, use of loop diuretics, bisphosphonates, or denosumab therapy [1]. Over time, NPHPT may progress to classical PHPT with its complications [72].

In the evaluation of PHPT, the calcium to creatinine clearance ratio is completed in order to exclude $\mathrm{FHH}$, a rare, autosomal-dominant disorder with three identified variants [73]. It usually presents with very low urinary calcium

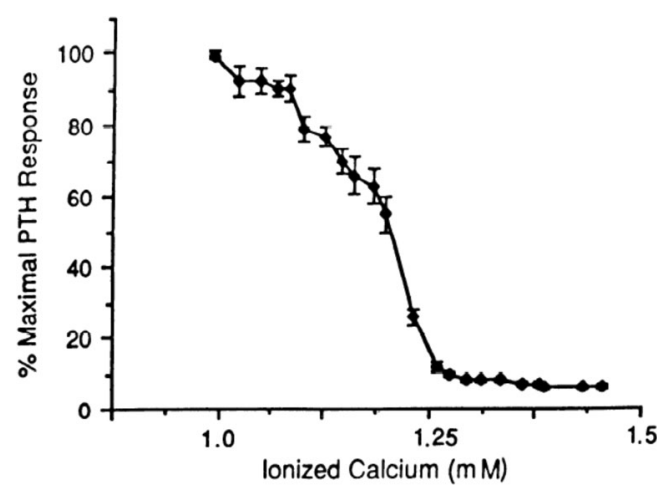

Fig. 1 Normal sigmoidal relationship between calcium and PTH [73] excretion and mild hypercalcemia with normal or slightly elevated PTH levels [74]. The most common variant, FHH1, is due to an inactivating mutation of the calcium-sensing receptor (CaSR) gene [69]. FHH2 is caused by inactivating mutations of the G-protein alpha 11 subunit $(\mathrm{G} \alpha 11)$ [73], and FHH3 is due to inactivating mutations of the adaptor protein 2 sigma subunit (AP2S1) [75]. DNA sequencing can confirm the presence of CaSR, G $\alpha 11$, or AP2S1 gene mutations and is advised in the following patients [73]: history of unsuccessful parathyroid surgery, age of onset of hypercalcemia under 30 years in the patient or relative, family history of hypercalcemia, or hypercalcemia and inappropriately high-normal or elevated PTH and calcium to creatinine clearance ratio $(\mathrm{CaCrCR})<0.02$.

$\mathrm{FHH}$ is unlikely if the $\mathrm{CaCrCR}$ is higher than 0.02 [74]. The majority $(80 \%)$ of individuals with $\mathrm{FHH}$ will have a $\mathrm{CaCrCR}$ of $<0.01$; however, approximately $20 \%$ have a $\mathrm{CaCrCR}$ between 0.01 and 0.02 and can overlap those with PHPT [74].

A low $\mathrm{CaCrCR}$ may be observed in PHPT with renal insufficiency or severe calcium and/or vitamin D deficiency. Racial differences also impact the laboratory profile. In those of African descent, the prevalence of low urine calcium excretion in patients with PHPT is very high, with approximately $44 \%$ of patients presenting with calcium excretion of $\leq 100 \mathrm{mg}$ /day in one study [74]. 
Patients with FHH should not undergo PTx, as the CaSR defect remains in the kidney and remaining parathyroid tissue, resulting in persistent hypercalcemia [74]. Mutations of the CaSR gene affecting both alleles can cause parathyroid hyperplasia with severe hypercalcemia and other classical features of PHPT [74, 76]. In this condition, PTx is recommended.

In children and young adults, PHPT is more commonly associated with hereditary forms of PHPT. Familial disorders, such as multiple endocrine neoplasia (MEN) types 1, 2A, and 4 , hyperparathyroidism jaw tumor syndrome, and familial isolated hyperparathyroidism (FIH), should be considered in individuals under 35 years old. Hereditary forms of PHPT should also be suspected in patients with other endocrine disorders or tumors as described below.

MEN-1 mutations are transmitted in an autosomal dominant manner and involve multiple endocrine tumors involving the parathyroids, pancreatic islets, and anterior pituitary and/or duodenal endocrine cells [71]. For MEN-1, most endocrine surgeons recommend subtotal PTx at the initial exploration because of the high risk of persistent and recurrent hyperparathyroidism [77].

Identification of mutations in the RET proto-oncogene is diagnostic of MEN-2a. Early diagnosis is imperative as MEN$2 \mathrm{a}$ is associated with medullary thyroid carcinoma. Confirmation of this germ line mutation should lead to prophylactic thyroidectomy, ideally before 6 years of age.

Hyperparathyroidism-jaw tumor syndrome (CDC73 gene mutation) is associated with tumors in the parathyroids, kidneys, uterus, mandible, and/or maxilla. As the parathyroid tumors can be malignant, the presence of a mutation in the $C D C 73$ gene in a patient with PHPT emphasizes the need for early PTx.

Thus, family history and DNA sequencing are of value in confirming the diagnosis as early as possible and preventing malignancies associated with hereditary hyperparathyroidism.

\section{What is the role of preoperative imaging in PHPT?}

Parathyroid glands are usually located at the four poles of the thyroid gland. Upper mediastinal tumors, while not in their expected location, are readily identified. However, parathyroid glands can be found in other locations and may be difficult to locate.

Parathyroid imaging has become a standard preoperative procedure to locate abnormal parathyroid tissue [69]. Parathyroid imaging is not a diagnostic procedure and is not advised unless surgical intervention is planned. Parathyroid adenomas or hyperplastic parathyroid glands are not always definitively identified. Lack of positive imaging should not preclude PTx in diagnosed patients as experienced parathyroid surgeons will find abnormal parathyroid glands regardless of imaging. The value of imaging rests with accurate identification of abnormal parathyroid tissue in order to assist in planning the appropriate parathyroid surgery. No level of imaging prowess substitutes for the expert parathyroid surgeon.

Preoperative parathyroid imaging studies have great utility during repeat neck surgery where scar tissue and distorted anatomical landmarks from previous operations make subsequent operations more difficult [78]. The imaging techniques most frequently used are ${ }^{99 \mathrm{~m}} \mathrm{Tc}$-sestamibi scintigraphy, ultrasound, and computed tomography (CT) [78]. In the presence of concordance between scintigraphy and ultrasound, the positive predictive value for correct side localization of a parathyroid adenoma can be as high as $97 \%$ [78].

\section{${ }^{99 m}$ Tc-sestamibi scintigraphy}

${ }^{99 \mathrm{~m}} \mathrm{Tc}$-sestamibi scintigraphy is based on the preferential uptake of sestamibi in the mitochondria-rich parathyroid adenoma cells. Physiologic uptake is also observed in the thyroid gland, the salivary glands, thymus (in young individuals), liver, mammary glands (during lactation), bone marrow, and brown adipose tissue. ${ }^{99 \mathrm{~m}} \mathrm{Tc}$-sestamibi scintigraphy is very sensitive (90\%) and highly accurate (97.2\%) in PHPT [78], with greater experience resulting in more reliable results [79]. Larger parathyroid adenoma $(>1.8 \mathrm{~cm})$ and higher preoperative ionized calcium levels $(>1.49 \mathrm{mmol} / \mathrm{L})$ are more reliably identified by sestamibi scan [78]. Low-dose ${ }^{99 \mathrm{~m}}$ Tc-sestamibi are as effective as high-dose protocols, but without the disadvantages of the higher doses [80]. There are several options for ${ }^{99 \mathrm{~m}}$ Tc-sestamibi scans available:

\section{Washout scintigraphy using a single isotope}

${ }^{99 \mathrm{~m}}$ Tc-sestamibi has a faster washout from thyroid tissue than from enlarged parathyroid glands, and tracer retention identifies the presence of hyperfunctioning parathyroid tissue. Antero-posterior scans are performed at 10-15 min postisotope administration and following washout (90-120 min). Delayed washout in a well-defined area suggests the location of the parathyroid adenoma.

\section{Subtraction scintigraphy}

Two isotopes are used to distinguish between uptake in the thyroid gland $\left({ }^{99 \mathrm{~m}} \mathrm{Tc}\right.$-pertechnetate and $\left.{ }^{123} \mathrm{I}\right)$ and both the thyroid and the parathyroids $\left({ }^{99 \mathrm{~m}} \mathrm{Tc}\right.$-sestamibi). Subtraction of the images may be visual or digital. A parathyroid adenoma may appear as an area of increased uptake or as a new upcoming configuration change on the ${ }^{99 \mathrm{~m}} \mathrm{Tc}$-sestamibi scintigraphy. Subtraction scintigraphy is superior to dual-phase scintigraphy for identification of single- or multiple-gland disease [81].

Addition of a single-photon emission computed tomography (SPECT) study alone or in combination with low-dose CT can improve localization of the parathyroid lesion [82]. The combination has been found to be superior to either 
technique alone [83]. Tomographic three-dimensional reconstruction allows improved separation between the activity in the thyroid gland and a parathyroid adenoma situated behind the thyroid. The CT scan more accurately reflects the anatomic location of the adenoma (Fig. 2). These techniques are especially helpful when planning repeat surgery [84].

A small parathyroid adenoma is the most frequent cause of false-negative scintigraphy. The mean volume of detected abnormal glands has been reported as $3.5 \mathrm{~cm}^{3}$, while the mean volume of missed glands is $1.4 \mathrm{~cm}^{3}[85,86]$.

The diagnostic sensitivity also depends on the adenoma's vascularity, perfusion, and cellular density. Sestamibi retention in "cold" or "warm" thyroid nodules may lead to falsepositive results and may not be as reliable in the presence of a multinodular thyroid. Sestamibi may be taken up in both benign (reactive lymphoid nodes, sarcoidosis) and malignant (primary tumors and metastases) tissues.

Combined ${ }^{99 \mathrm{~m}} \mathrm{Tc}$-sestamibi and ${ }^{99 \mathrm{~m}} \mathrm{Tc}$ scintigraphy with SPECT is now routinely performed preoperatively in developed countries with a sensitivity of $79 \%$ and a positive predictive value of $91 \%$ [87]. In patients requiring repeat surgery due to persistent PHPT, the localization rates are lower with ${ }^{99 \mathrm{~m}}$ Tc-sestamibi-SPECT [87].

\section{Ultrasound of parathyroid glands}

By ultrasound, a parathyroid adenoma is usually seen as a round or oval well-defined, hypoechogenic structure delineated by an echogenic line and contrasting the overlying hyperechogenic thyroid tissue (Fig. 3). Calcifications and cysts may be found in larger parathyroid adenomas. Normal parathyroid glands are usually approximately $4 \mathrm{~mm}$ in size and not detected by ultrasound. Ultrasound is most useful in identifying parathyroid adenoma close to the thyroid gland or the upper cervical portion of the thymus. Ultrasound is less useful in identifying parathyroid adenomas located behind the trachea or esophagus or ectopic glands in the mediastinum. Ultrasound may be useful as a supplemental study to confirm the localization of a parathyroid adenoma identified by ${ }^{99 \mathrm{~m}}$ sestamibi scintigraphy.

The sensitivity of ultrasonography is $76-87 \%$ with a positive predictive value of 93-97\% and a diagnostic accuracy of $88 \%$ [87]. Additionally, ultrasound can identify concurrent thyroid nodules that may require biopsy prior to PTx.

\section{${ }^{11}$ C-Methionine PET/CT scintigraphy}

This method is based on the uptake and incorporation of the essential amino acid methionine in parathyroid tissue in PTH synthesis. It may have a high sensitivity even in patients where conventional investigations have failed [88]. This modality is expensive and not widely available.

\section{Magnetic resonance imaging}

A parathyroid adenoma appears as a soft tissue mass with high signal intensity on T2-weighted frames but low to moderate in T1-weighted frames. The signal intensity of the parathyroid adenoma is enhanced after gadolinium injection on $\mathrm{T} 1$ weighted frames compared with thyroid tissue with a sensitivity of approximately $50 \%$. Lymph nodes may have the same appearance. Gadolinium should not be used in patients with decreased renal function. This study is less commonly used except in certain circumstances such as during pregnancy due to lack of ionizing radiation as it has a lower sensitivity in comparison to four-dimensional CT (4D-CT) scans (see below). MRI may identify adenomas missed by sestamibi analysis [89]. The combination of the two modalities is superior to either alone [89].

\section{Conventional CT}

$\mathrm{CT}$ after contrast injection is a valuable imaging tool of particular benefit in localizing ectopic mediastinal parathyroid glands [90]. The sensitivity of CT is approximately 46$87 \%$. CT imaging allows rapid assessment of the parathyroids. Disadvantages include exposure to radiation, cost, and need for iodinated contrast. Two-phase CT was found to be as accurate as four-phase CT for diagnostic accuracy in localizing abnormal parathyroid glands, and with less radiation exposure [90].

4D-CT can be a useful imaging tool. The fourth dimension refers to time (please refer to Fig. 2 for 4D-CT images). This technique is the initial imaging of choice over ultrasound and sestamibi scans at a few centers in North America. The increased sensitivity of $\mathrm{CT}$ in identifying normal and abnormal parathyroid tissue has significantly enhanced the localization of abnormal tissue preoperatively [91].

\section{Selective venous sampling with PTH measurement}

This technique is expensive and requires an experienced angiographer. It is only appropriately performed in the setting of a remedial exploration (in patients with previously unsuccessful surgery) when non-invasive imaging studies are noninformative [92]. In one study, preoperative venous sampling had a significantly higher sensitivity $(75 \%)$ than ${ }^{99 \mathrm{~m}} \mathrm{Tc}-$ sestamibi-SPECT (30\%) [92].

\section{Management and treatment}

\section{What is the role of surgery in PHPT?}

Patients with symptomatic PHPT as well as asymptomatic patients who meet any one of the guideline criteria should be advised to undergo PTx, unless contraindications exist (see 
Fig. 2 a 4D-CT images of left paraesophageal parathyroid adenoma with feeding vessel.

Arterial, $2 \mathrm{~mm}$ slices, adenoma measured $8 \times 4 \times 14 \mathrm{~mm}$ on $\mathrm{CT}$ (images supplied by Drs. Bart

Clarke and Geoffrey B.

Thompson of the Mayo

Department of Endocrine

Surgery, Rochester, MN). b 4D-

CT images of left paraesophageal parathyroid adenoma with feeding vessel. c 4D-CT images of left paraesophageal parathyroid adenoma with feeding vessel a
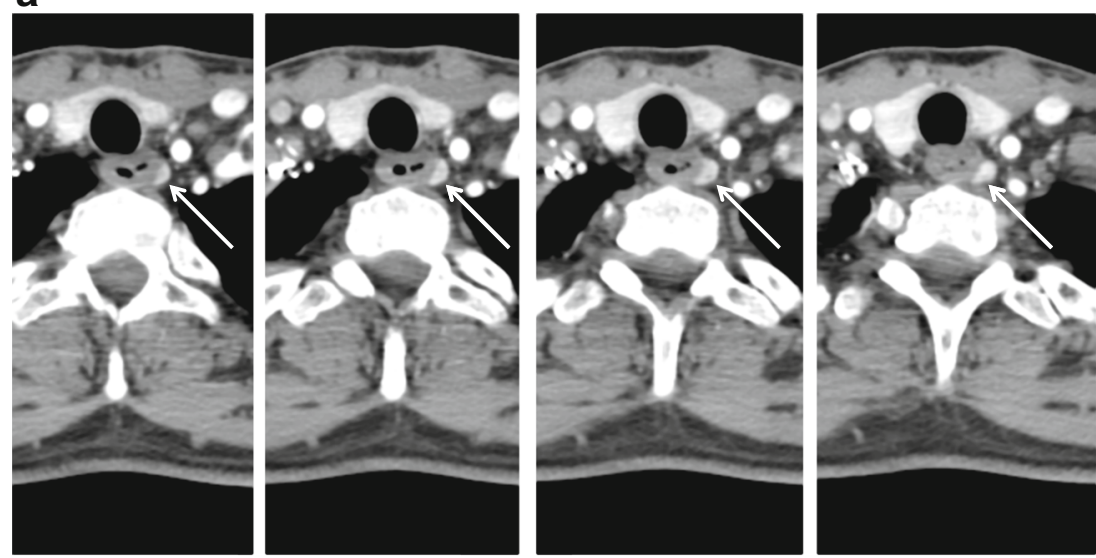

b
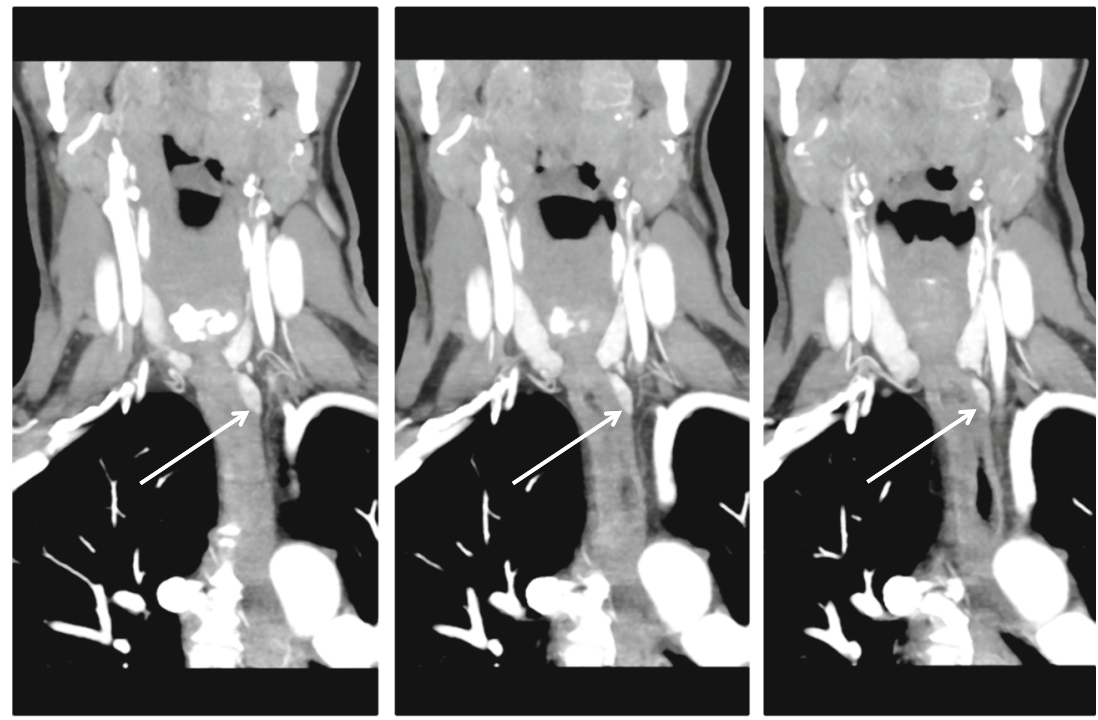

C
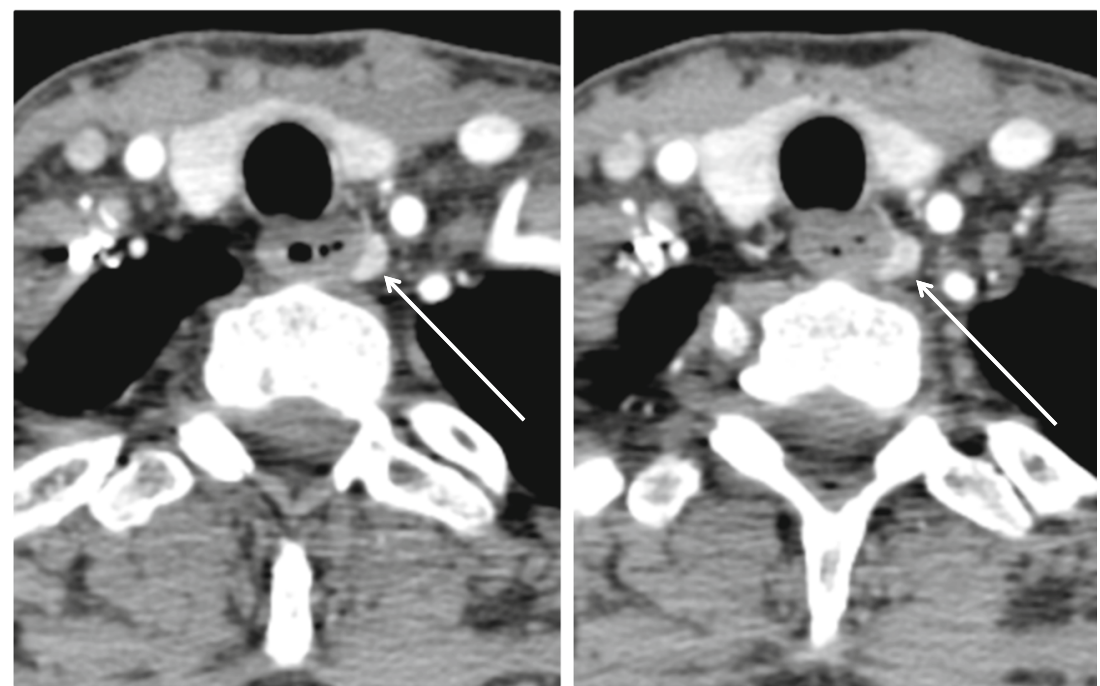

below). Surgical consultation can be offered to those who do not meet guidelines for surgery. Data from cohort studies have demonstrated reductions in the risk of all fractures post-PTx
$[16,17]$. Also renal stone risk decreases following PTx [11, 93]. Normalization of serum calcium and PTH may have additional long-term benefits which have not yet been confirmed in 
Fig. 3 99mTC-sestaMIBIscintigraphy with SPECT and low-dose CT

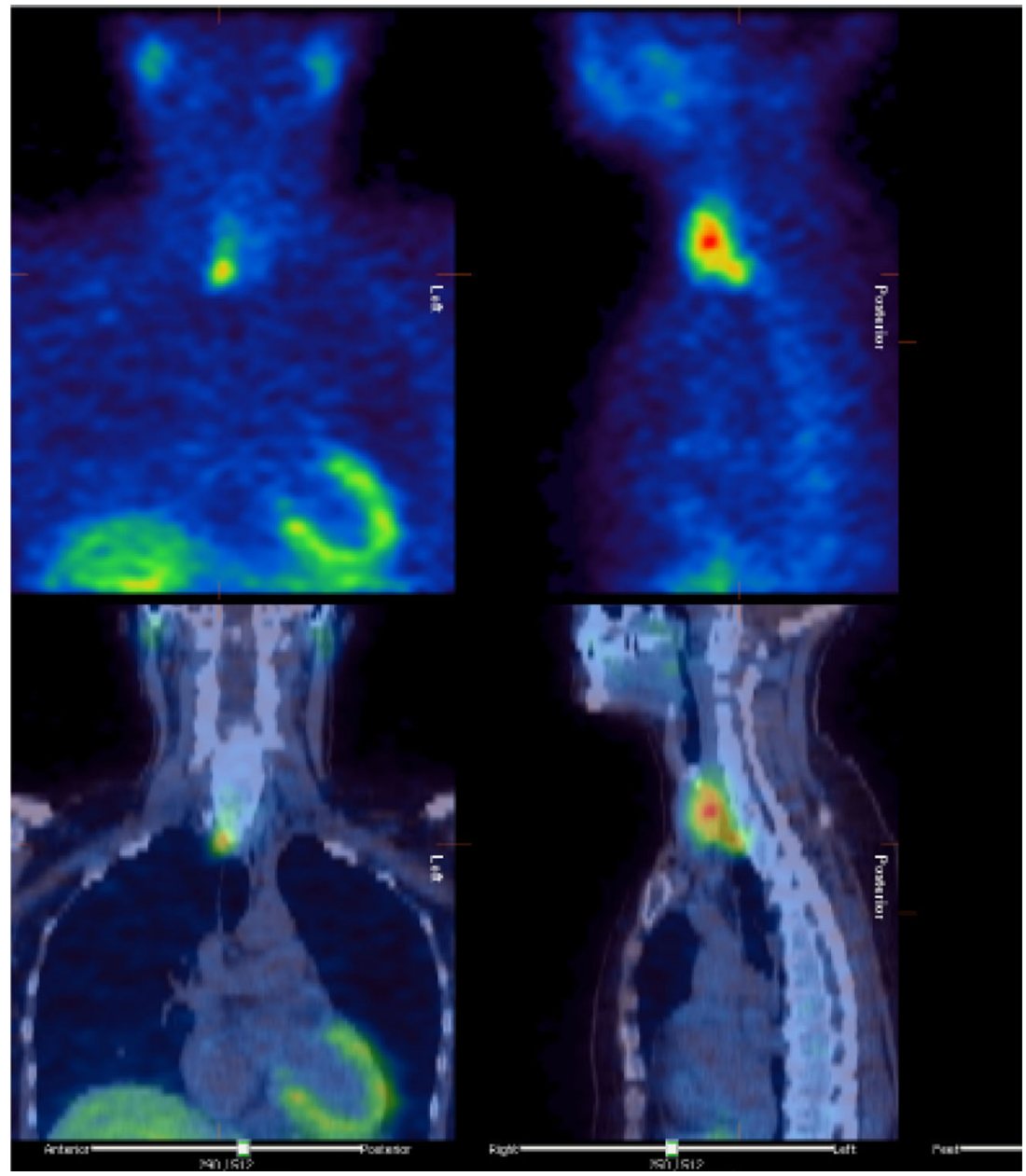

large long-term randomized controlled trials. For these reasons, PTx is always appropriate if the diagnosis has been confirmed and in the absence of contraindications or significant co-morbidity. Cure rates following PTx in the hands of an experienced surgeon exceed $95 \%$ with a very low complication rate $(<1-$ $3 \%$ ) [94]. In individuals with a single adenoma, (seen in $~ 85 \%$ of PHPT patients), surgery can be curative. In the $15 \%$ of patients with hyperplasia, the risk of recurrence is greater and often requires a subtotal PTx. These patients are at higher risk of recurrent disease as the remnant left in situ is, by definition, abnormal and subject to further growth.

Parathyroid carcinoma occurs in $<1 \%$ of patients with PHPT. A parathyroid gland suspicious for a carcinoma discovered during the initial operation should immediately undergo en bloc resection of the parathyroid lesion and the ipsilateral thyroid lobe together with any invaded muscles [94].

In addition to improvements in bone remodeling and BMD post-PTx, benefits may include improvements in cardiac and vascular function [95]. Recurrent urolithiasis is reduced postPTx but not eliminated, particularly in patients previously categorized as idiopathic stone formers [96]. Persistently increased fractional excretion of calcium post-PTx was seen in one study which may explain the sustained increased risk of stone disease for many years after successful PTx [97]. Even asymptomatic PHPT patients display clinical improvement in some symptoms a year following PTx, particularly patients with higher preoperative calcium levels $(\geq 2.6 \mathrm{mmol} / \mathrm{L})$ and those who are younger ( $<70$ years) [94].

\section{Who should have surgery?}

All individuals with symptomatic PHPT should have surgery. The benefits include relief of hypercalcemic symptoms and improvements in skeletal [94] and renal [10] health. Additional benefits may include cardiovascular, neurologic, and gastrointestinal health; however, these potential benefits require further confirmation in large randomized controlled trials [94].

In asymptomatic PHPT, the value of PTx is emphasized, as surgery corrects the underlying abnormality and improves $\mathrm{BMD}$, lowers bone turnover, and improves fracture-free survival [2]. The indications for surgery according to the 4 th International Guidelines for the Management of Asymptomatic PHPT [2] are presented in Table 2. 
Table 2 Indications for surgery for the treatment of primary hyperparathyroidism.
1) Age $<50$ years.

2) Serum calcium $>1 \mathrm{mg} / \mathrm{dL}$ or $>0.25 \mathrm{mmol} / \mathrm{L}$ of the upper limit of the reference interval for total calcium and $>0.12 \mathrm{mmol} / \mathrm{L}$ for $\mathrm{Ca}^{2+}$.

3) BMD T-score $\leq-2.5$ at the lumbar spine, femoral neck, the total hip, or the $1 / 3$ radius for postmenopausal women or males $>50$ yrs. A prevalent low-energy fracture (i.e., in the spine) is also considered an indication for surgery, which requires a routine X-ray of the thoracic and lumbar spine (or vertebral fracture assessment by DXA).

4) A glomerular filtration rate (GFR) of $<60 \mathrm{ml} / \mathrm{min}$. Further evaluation of asymptomatic patients with renal imaging (X-ray, CT or ultrasound) in order to detect silent kidney stones or nephrocalcinosis is advised [2]. A complete urinary stone risk profile should be performed in those individuals whose urinary calcium excretion is > $400 \mathrm{mg}$ /day. If stone(s), nephrocalcinosis, or high stone risk is determined, surgery should be recommended.

\section{Younger and older populations}

Parathyroidectomy is advised for those with PHPT under 50 years of age, including children. In children, PTx has similar success rates with rapid increases in BMD [98]. In adolescents, the disease was more severe than in adults in one study [98]. Similar surgical success rates were seen in adolescents in comparison to adults [99]. In patients younger than 45 years, minimally invasive PTx has a recurrence rate similar to older individuals [94].

Surgery is recommended in older individuals meeting criteria for PTx if they are medically stable with no contraindications for surgery and/or the benefits of surgery outweigh the risks [100]. Advancing age is associated with greater morbidity, intraoperative and post-operative complications, and higher mortality rates following PTx [101].

\section{Indications for minimally invasive parathyroidectomy}

With successful preoperative localization of a parathyroid adenoma, minimally invasive parathyroid (MIP) surgery has become widely used. MIP has high surgical success rates (95$98 \%)$ and low complication rates (1-3\%) similar to those seen with the classical open PTx [94]. Reduced operative time, outpatient surgery, reduced costs, and fewer complications are all benefits of the MIP [94].

An "open" PTx is preferred if preoperative imaging has not identified a parathyroid adenoma [94] or if hyperplasia or familial disease is suspected [94]. A bilateral neck exploration and subtotal PTx is usually performed in patients with MEN-1 or lithium-induced PHPT.

The MIP approach can be extended to a bilateral neck exploration if a parathyroid adenoma cannot be found or if the patient has unsuspected multiglandular disease. Multiglandular PHPT may not be excluded before surgery and is seen in approximately one in ten patients with sporadic PHPT [94]. In selected patients with MEN-1, MIP with excision of only the abnormal parathyroid glands may provide an acceptable outcome [102]. However, recurrence rates are expected to be higher.
Measuring PTH intraoperatively (IOPTH) with a rapid assay is of value in confirming adequate resection of abnormal parathyroid tissue and increases surgical success rates [94, 103]. The half-life of PTH is approximately 3 to $5 \mathrm{~min}$. PTH is measured 5 and 15 min following resection of the parathyroid adenoma. IOPTH is obtained with a rapid PTH assay [94]. If the PTH level decreases by at least $50 \%$ and falls into the normal range following resection, this confirms that adequate tissue has been resected and further exploration is not necessary [94].

A highly experienced surgeon can comfortably conduct a bilateral procedure visualizing all four parathyroid glands if the PTH level does not decrease into the normal reference range [94].

Repeat surgery is necessary in up to $5 \%$ of individuals with persistent PHPT defined as the development of hypercalcemia within 6 months of PTx and is due to incomplete resection of abnormal parathyroid tissue. Recurrent disease as compared to persistent disease reflects the development of PHPT anew and occurs in up to $8 \%$ of individuals with a sporadic parathyroid adenoma after 3-11 years [94]. Patients with double parathyroid adenomas have a higher rate of recurrent PHPT $(4.0 \%)$ as compared to patients with a single adenoma (1.3\%) or hyperplasia (2.2\%) [94]. Localization studies should be performed before reoperations to identify ectopic glands, although in most cases the abnormal glands are located in eutopic positions. The reoperation is best planned as a focused intervention when the presumed tumor is localized or as a unilateral exploration on the side that has not been explored previously [94]. Employment of an IOPTH assay is very helpful in remedial cases. Reoperation has a high success rate (>90\%) [94], especially when the pathologic parathyroid tissue is localized preoperatively. However, the risk of complications is higher in connection with a reoperation [94]. Cryopreservation of removed parathyroid tissue should be considered and used for subsequent auto-transplantation when permanent postoperative hypoparathyroidism is a real consideration. The success of PTx is influenced by patient age, surgeon's expertise, and hospital endocrine surgery volume, as well as the results of preoperative imaging [94]. 


\section{Who should be monitored without surgery and what are the medical options?}

Monitoring appears to be a safe option for possibly up to 8 to 10 years for patients with asymptomatic PHPT who do not meet guidelines for surgery or are unable or unwilling to undergo PTx. BMD assessments on a 1-to-2-year basis in addition to yearly monitoring of the biochemical profile are recommended. Calcium intake should be recommended without restrictions according to the Institute of Medicine Guidelines [104], and vitamin D levels should be sufficient.

\section{Vitamin D}

Vitamin D deficiency and insufficiency occur in many patients with PHPT [69]. In Southern Europe, vitamin D insufficiency $(<50 \mathrm{nmol} / \mathrm{L})$ was present in approximately one third of patients with PHPT (higher than that of matched controls at $11 \%)$ and was related to more severe skeletal disease [105]. As there is a 1000:1-M ratio between serum 25OHD and serum 1,25-dihydroxyvitamin $\mathrm{D}\left(1,25(\mathrm{OH})_{2} \mathrm{D}\right)$, it is unlikely that PTH-stimulated conversion of $25 \mathrm{OHD}$ to $1,25(\mathrm{OH})_{2} \mathrm{D}$ explains the reduction in serum 25OHD in PHPT. It is probable that elevated $1,25(\mathrm{OH})_{2} \mathrm{D}$ levels stimulate 24 hydroxylase gene expression and enhanced conversion of $25 \mathrm{OHD}$ to 1,24 -dihydroxy vitamin $\mathrm{D}$ [106]. Co-existing vitamin D insufficiency has been associated with increased parathyroid gland weight; higher plasma levels of PTH, calcium, and alkaline phosphatase; lower plasma phosphate levels; and lower total hip and forearm BMD and cortical BMD [107, 108].

Vitamin D inadequacy appears to be associated with a more severe bone disease [109] and, consequently, a greater risk of hungry bone syndrome following PTx. In a 1-year study of 21 patients, vitamin D supplementation in PHPT was safe and effective in lowering PTH levels by up to $26 \%$ without increasing mean serum calcium or urinary calcium excretion, although two patients had urinary calcium excretion above $400 \mathrm{mg}$ [110]. The effects on bone markers and BMD are not conclusive [106]. Occasionally, vitamin D treatment may increase serum calcium levels and renal calcium excretion. A randomized, placebo-controlled study of vitamin D supplementation (2800 IU daily) for 26 weeks prior to PTx showed a significant $17 \%$ decrease in serum PTH and a $2.5 \%$ increase in lumbar BMD in the treated group without side effects [108].

In a randomized clinical trial, vitamin D supplementation for a year lowered PTH levels with no effects on serum calcium [108]. It is recommended that vitamin D deficiency/ insufficiency be corrected and optimal vitamin D levels $>50 \mathrm{nmol} / \mathrm{L}$ be maintained [2], or even at $>75 \mathrm{nmol} / \mathrm{L}$ $(30 \mathrm{ng} / \mathrm{mL})[2]$.
Antiresorptive therapy

Amino-substituted bisphosphonates and hormone replacement therapy (HRT) improve BMD and lower biochemical markers of bone turnover in patients with PHPT. However, fracture studies are not available.

Table 3 provides a summary of the clinical trials evaluating amino-bisphosphonate therapy in PHPT. A meta-analysis has shown increases in hip and lumbar spine BMD with antiresorptive therapy to be similar to the improvements seen post-PTx [118]. In very limited studies, raloxifene has been associated with BMD improvements in subjects with PHPT [119].

Estrogen therapy decreases bone turnover, reduces urinary calcium excretion, and increases BMD throughout the skeleton in post-menopausal women with mild PHPT [120]. Reductions in ionized calcium or PTH have not been seen with estrogen therapy. There are no fracture data with estrogen therapy in PHPT.

Antiresorptive treatment should be considered in those with T-scores equal to or below -2.5 at the lumbar spine, hip, or one-third radius, or in the presence of fragility fractures in patients who are unable or unwilling to undergo PTx.

\section{Cinacalcet}

Cinacalcet, a calcimimetic agent, lowers serum calcium and PTH by increasing the sensitivity of the CaSR to extracellular calcium, thereby decreasing serum PTH and reducing the renal tubular reabsorption of calcium. With cinacalcet, serum calcium normalizes in $70-80 \%$ of patients with PHPT [121]. The effect is maintained over 5 years; however, serum calcium increases to baseline levels when treatment is stopped. This drug does not impact BMD or lower biochemical markers of bone turnover [121]. There are no documented effects on hypercalcemic symptoms, renal stones, or quality of life.

Combination therapy with alendronate and cinacalcet has been evaluated retrospectively over 12 months and resulted in greater improvements in BMD at the lumbar spine and total hip sites in comparison to cinacalcet alone. Reductions in serum calcium to normal were noted in both the combination as well as the cinacalcet-only arms [122].

In a phase 3, multicenter RCT, 67 subjects with moderate PHPT unable to undergo PTx were randomized (1:1) to cinacalcet or placebo for 28 weeks [123]. Serum Ca normalized in $75.8 \%$ of cinacalcet-treated vs $0 \%$ of placebotreated subjects $(P<0.001)$. The drug was well tolerated with similar adverse events in both groups. Side effects were limited to nausea and muscle spasms. Table 4 provides a summary of the trials evaluating cinacalcet in the treatment of PHPT. 


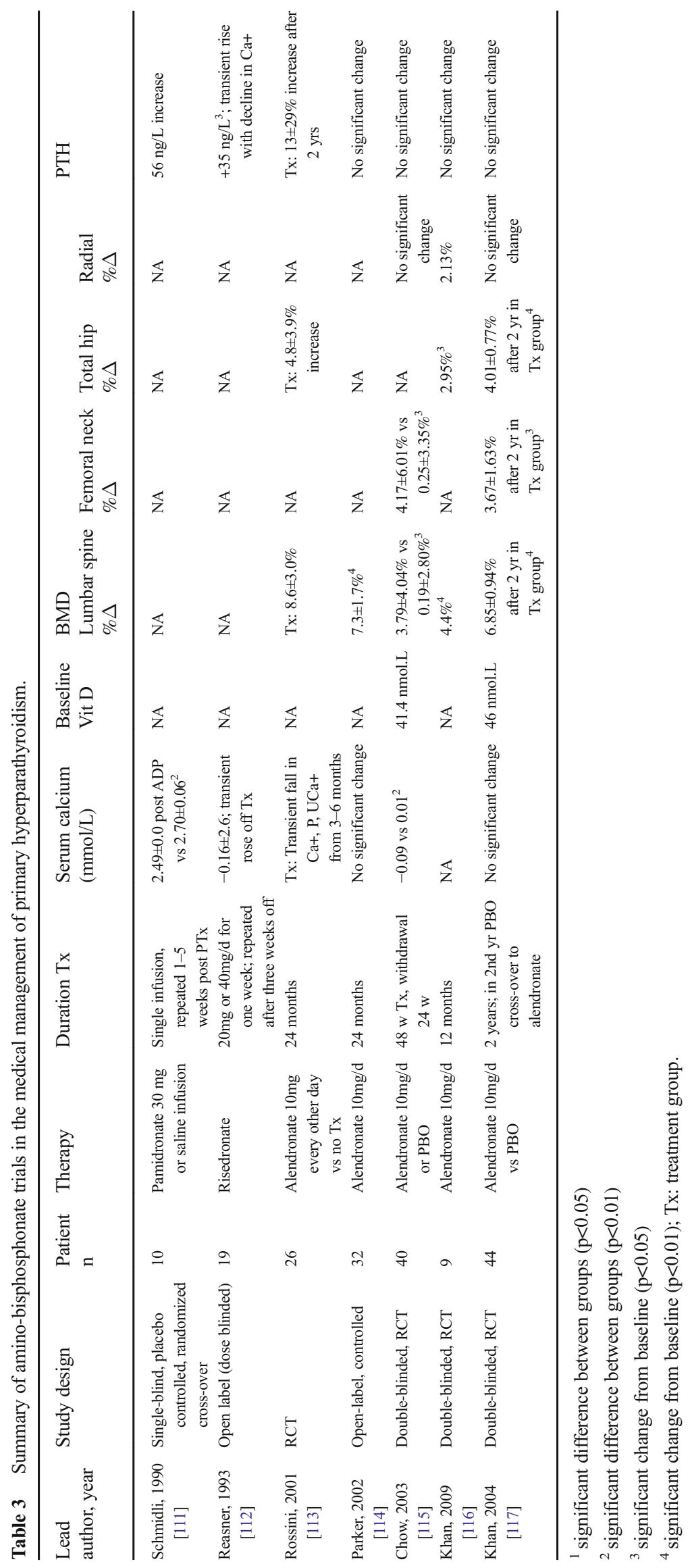




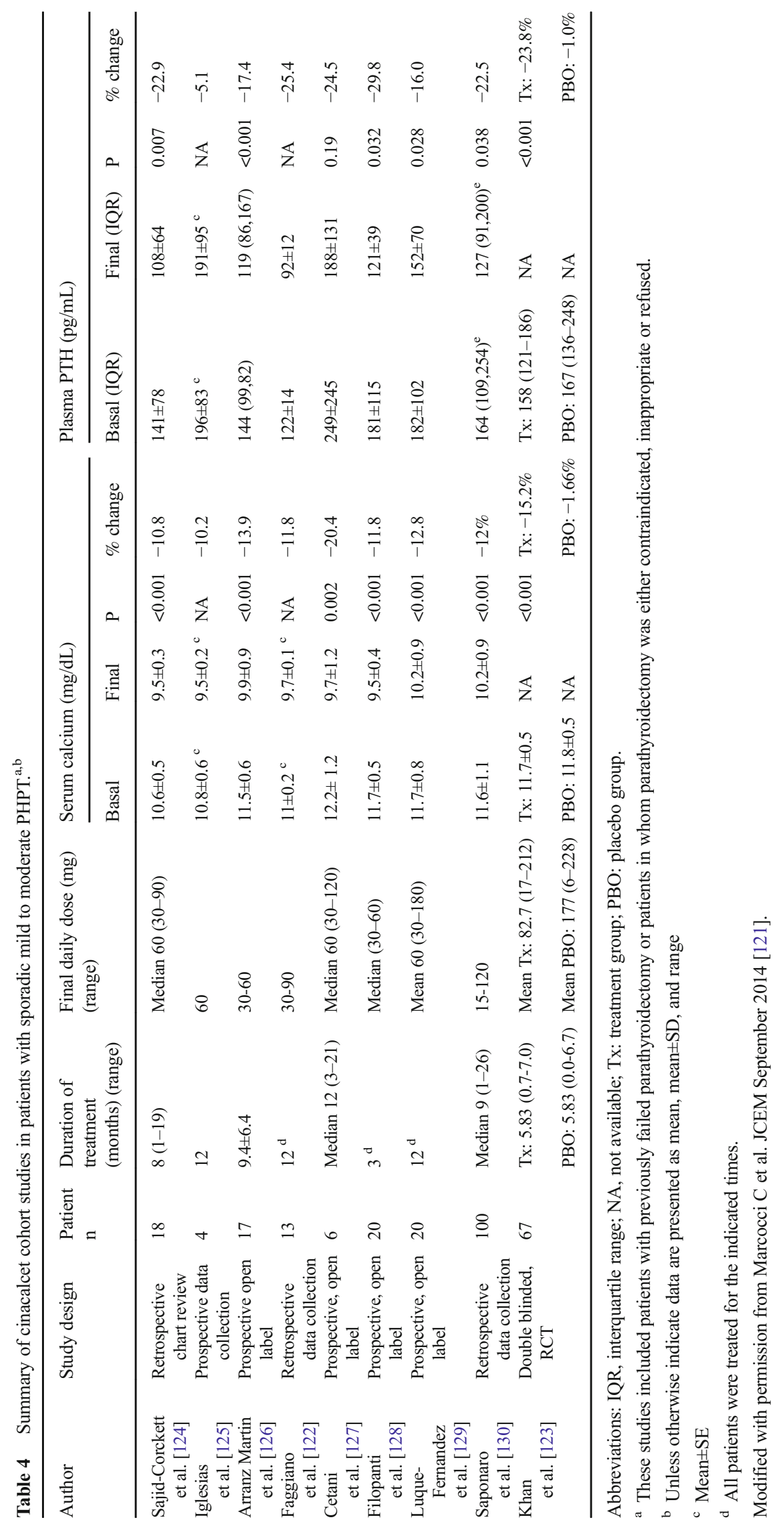


At this time, cinacalcet is not recommended as a first-line treatment choice for the management of PHPT. Cinacalcet is a useful option in symptomatic patients where the disease cannot be controlled by surgical intervention or in circumstances where surgery is contraindicated and in patients with unresectable parathyroid cancer.

Currently, the only alternative to surgery demonstrated to lower serum calcium in PHPT is cinacalcet. The costs of cinacalcet may limit its access in certain patients and need to be taken into consideration in determining management strategies (Table 5).

\section{How should PHPT be evaluated and treated during pregnancy?}

PHPT is far less common in women of childbearing age, with an estimated prevalence of $8 / 100,000$ women [131]. Hypercalcemia in pregnancy may be masked by several factors including increased extracellular fluid volume, low serum albumin, and increased transport of calcium to the fetus. PHPT in pregnancy has been associated with hyperemesis, miscarriage, nephrolithiasis, life-threatening hypercalcemic crisis, and pancreatitis. PHPT may be associated with intrauterine growth retardation and fetal death, preterm delivery,

Table 5 PHPT: Key points and what is new.

A. Diagnosis

1. Confirmed if serum calcium is elevated (total calcium corrected for albumin or elevated ionized calcium) in the presence of an elevated or inappropriately normal PTH in the absence of conditions mimicking PHPT (thiazide diuretics or lithium) and FHH.

2. FHH - Three variants now identified. Confirmed by DNA analysis of CaSR gene, G $\alpha 11$ gene or AP2S1 genes. Suspected if CaCrCR $<0.01$. However in $20 \%$ of FHH cases CaCrCR can overlap with PHPT and is 0.01-0.02.

3. Consider familial PHPT in children and adults $<35$ years of age and DNA analysis (MEN1 gene, RET oncogene, HRPT2 gene) in the presence of:

a. Family History of hypercalcemia

b. Prior unsuccessful parathyroid surgery in patient or relative

c. Hypercalcemia identified at young age $(<25 \mathrm{yrs})$ in patient or relative

d. Absence of symptoms of hypercalcemia

e. $\mathrm{CaCrCR}<0.02$

\section{B. Imaging:}

1. Imaging is not used for the diagnosis of PHPT, which is based on biochemical profile.

2. Identification of abnormal parathyroid tissue is enhanced with single photon emission computed tomography (SPECT) study in combination with a computed tomography (CT) study and is particularly valuable in repeat surgical cases.

3. Ultrasound, $99 \mathrm{~m} \mathrm{Tc}$-sestamibi scintigraphy continue to be useful localization tools, however, they can miss small adenomas and hyperplasia.

4. Additional imaging or localization tools for those failing surgery or suspected of having an ectopic parathyroid gland include CT scans, MRI (Magnetic Resonance Imaging), ${ }^{11}$ C-Methionine PET/CT Parathyroid Scintigraphy. Selective venous sampling should only be performed when required for remedial exploration.

\section{Presentation:}

1. In developed countries - approximately $85 \%$ of patients present with asymptomatic disease. Twenty \% present with renal complications (kidney stones, nephrocalcinosis), skeletal complications (fracture, osteitis fibrosa cystica, bone pain) or symptomatic hypercalcemia.

2. In developing countries the majority of patients present with symptomatic disease.

D. Indications for Parathyroid Surgery

1. All symptomatic PHPT

2. Asymptomatic PHPT - surgery is a valuable option particularly in those meeting criteria for surgical intervention.

\section{E. Medical Management}

1. Vitamin D deficiency/insufficiency should be corrected and is effective in lowering serum PTH without further elevating serum calcium. Correct serum $25 \mathrm{OHD}$ to $>50 \mathrm{nmol} / \mathrm{L}$.

2. Amino-bisphosphonates are effective in preventing decreases in BMD and lowering bone remodelling.

3. Cinacalcet is effective in lowering serum calcium and should be considered for symptomatic PHPT when surgery is not an option. Aminobisphosphonates may be used in combination with cinacalcet in selected patients.

4. Data with medical therapy currently is short-term and insufficient to justify medical therapy as an alternative to surgery. There is no fracture data with any of the existing medical therapies. 
neonatal hypocalcemic tetany, or seizures [132]. The most common cause of PHPT in pregnancy appears to be a single parathyroid adenoma.

Ultrasonography is the preferred modality for localizing the parathyroid lesion. PHPT in pregnancy requires close monitoring of both the mother and the fetus. Treatment of PHPT in pregnancy is recommended if the serum calcium $>12 \mathrm{mg} / \mathrm{dL}$ ( $3 \mathrm{mmol} / \mathrm{L}$ ), and intervention is determined by the stage of gestation, severity and symptoms of hypercalcemia, and patient preference. All patients should be advised to ensure adequate hydration. If the ionized calcium is above $0.12 \mathrm{mmol} / \mathrm{L}$ of upper normal levels [133], PTx in the second trimester is recommended [132]. Other treatment options include cinacalcet; however, fetal safety and outcome data are not available at this time.

\section{Summary}

PHPT presents at an asymptomatic stage in developed countries, while it remains a symptomatic disease in the developing world, although a larger number of individuals are now presenting with asymptomatic disease in Asia. PTx is curative in experienced hands and remains essential in those with symptomatic disease. In those with asymptomatic disease, surgery is also appropriate, particularly in those who meet surgical guidelines. Cohort data have demonstrated reductions in the risk of all fractures post-PTx. Surgery has also been shown to reduce the risk of renal stones and offers a cure if successful. Similar benefits have not yet been demonstrated with the existing medical options available. Medical monitoring appears to be safe for individuals who do not meet surgical guidelines and is required for those with contraindications for surgery or who are unwilling to undergo surgery. Targeted medical therapy includes amino-bisphosphonates for skeletal protection and cinacalcet for lowering serum calcium. There are no data showing fracture risk reduction with either antiresorptive therapy or with cinacalcet.

Future research should focus on the effects of PHPT on skeletal strength as well as pharmacologic approaches to lowering fracture risk. The effects of PHPT on cognition and the cardiovascular, gastrointestinal, and musculoskeletal systems in patients with mild asymptomatic disease require further evaluation with well-designed prospective cohort studies. The impact of attaining vitamin D sufficiency on PHPT also requires study. A greater understanding of the pathophysiology and natural history of NPHPT is an area of future research. Further progress in preoperative imaging will facilitate appropriate utilization of minimally invasive surgical interventions. The potential benefits of surgery as well as medical intervention are also areas requiring further exploration.

\section{Compliance with ethical standards}

Conflict of interest AA Khan is on the advisory board for Amgen, Eli Lilly, and Merck; has research grants from NPS, Amgen, and Merck; and has received lecture fees from Amgen, Eli Lilly, Warner Chilcott, and Merck; D Hanley has received funding for grants from Amgen, Eli Lilly, Merck, and Novartis; has received funding for lectures from Amgen Eli Lilly and Novartis; and is on the membership board for Amgen, Eli Lilly, Merck, and Novartis; R Rizzoli received consultancy and lecture fees from Amgen, Eli Lilly, MSD, Danone, and Servier; L Rejnmark received consultancy and lecture fees from NPS Pharmaceuticals, Amgen, Eli Lilly, and Novo Nordic; RV Thakker is a chairman of Astra-Zeneca Stratified Medicine Panel and has received lecture and consultancy fees from Novartis, Eli Lilly, AstraZeneca, and Ipsen; S Kaiser has received consultancy fees from Amgen and Eli Lilly and has received lecture fees from Amgen, Eli Lilly, Merck, and NRS; L Mosekilde has received funds for the development of educational presentations; DS Rao is on the advisory board for Diasorin Inc., has received consultancy fees from NPS Pharmaceuticals, has received grants from NIAMS, and has received funding for lectures from Eli Lilly; M Lewiecki has received research grant support from Amgen, Merck, and Eli Lilly and has received consultancy fees from Amgen, Eli Lilly, Merck, Radius Health, AgNovos Healthcare, Theranova, and Alexion; R Eastell received grants, lecture fees, and travel expenses from Amgen, AstraZeneca, IDS, Eli Lilly, Merck, Novartis, Roche, Alexion, Otsuka, IBMS, and Warner Chilcott; KS Davison has received honorarium for lectures from Novartis, Merck, Amgen, and Eli Lilly; and ML Brandi has received consultancy fees and grant funding from Amgen, Eli Lilly, MSD, Novartis, Roche, and Servier.

Funding This work was supported by the Calcium Disorders Clinic, McMaster University Hamilton, Ontario, Canada.

Open Access This article is distributed under the terms of the Creative Commons Attribution-NonCommercial 4.0 International License (http:// creativecommons.org/licenses/by-nc/4.0/), which permits any noncommercial use, distribution, and reproduction in any medium, provided you give appropriate credit to the original author(s) and the source, provide a link to the Creative Commons license, and indicate if changes were made.

\section{References}

1. Silverberg SJ, Clarke BL, Peacock M, Bandeira F, Boutroy S, Cusano NE, Dempster D, Lewiecki EM, Liu JM, Minisola S, Rejnmark L, Silva BC, Walker MD, Bilezikian JP (2014) Current issues in the presentation of asymptomatic primary hyperparathyroidism: proceedings of the Fourth International Workshop. J Clin Endocrinol Metab 99:3580-3594

2. Bilezikian JP, Brandi ML, Eastell R, Silverberg SJ, Udelsman R, Marcocci C, Potts JT Jr (2014) Guidelines for the management of asymptomatic primary hyperparathyroidism: summary statement from the Fourth International Workshop. J Clin Endocrinol Metab 99:3561-69

3. Khan AA (2013) Medical management of primary hyperparathyroidism. J Clin Densitom 16:60-63

4. Khan AA, Hanley DA, O'Brien CJ, Ste-Marie LG, Rotstein LE, Rosen I, Young JEM, Josse RG, Bilezikian JP (2003) Asymptomatic primary hyperparathyroidism - standards and 
guidelines for diagnosis and management in Canada. Endocr Pract 9:400-405

5. Ambrogini E, Cetani F, Cianferotti L, Vignali E, Banti C, Viccica G, Oppo A, Miccoli P, Berti P, Bilezikian JP, Pinchera A, Marcocci C (2007) Surgery or surveillance for mild asymptomatic primary hyperparathyroidism: a prospective, randomized clinical trial. J Clin Endocrinol Metab 92:3114-21

6. Bollerslev J, Jansson S, Mollerup CL, Nordenstrom J, Lundgren E, Torring O, Varhaug JE, Baranowski M, Aanderud S, Franco C, Freyschuss B, Isaksen GA, Ueland T, Rosen T (2007) Medical observation, compared with parathyroidectomy, for asymptomatic primary hyperparathyroidism: a prospective, randomized trial. J Clin Endocrinol Metab 92:1687-92

7. Rao DS, Phillips ER, Divine GW, Talpos GB (2004) Randomized controlled clinical trial of surgery versus no surgery in patients with mild asymptomatic primary hyperparathyroidism. J Clin Endocrinol Metab 89:5415-22

8. Rubin MR, Bilezikian JP, McMahon DJ, Jacobs T, Shane E, Siris E, Udesky J, Silverberg SJ (2008) The natural history of primary hyperparathyroidism with or without parathyroid surgery after 15 years. J Clin Endocrinol Metab 93:3462-70

9. Lundstam K, Heck A, Mollerup C, Godang K, Baranowski M, Pernow Y, Varhaug JE, Hessman O, Rosen T, Nordenstrom J, Jansson S, Hellstrom M, Bollerslev J (2015) Effects of parathyroidectomy versus observation on the development of vertebral fractures in mild primary hyperparathyroidism. J Clin Endocrinol Metab 100:1359-67

10. Rejnmark L, Vestergaard P, Mosekilde L (2011) Nephrolithiasis and renal calcifications in primary hyperparathyroidism. J Clin Endocrinol Metab 96:2377-85

11. Mollerup CL, Vestergaard P, Frokjaer VG, Mosekilde L, Christiansen P, Blichert-Toft M (2002) Risk of renal stone events in primary hyperparathyroidism before and after parathyroid surgery: controlled retrospective follow up study. BMJ 325:807

12. Parks JH, Coe FL, Evan AP, Worcester EM (2009) Clinical and laboratory characteristics of calcium stone-formers with and without primary hyperparathyroidism. BJU Int 103:670-678

13. Tassone F, Guarnieri A, Castellano E, Baffoni C, Attanasio R, Borretta G (2015) Parathyroidectomy halts the deterioration of renal function in primary hyperparathyroidism. J Clin Endocrinol Metab 100:3069-73

14. Miller PD, Bilezikian JP (2002) Bone densitometry in asymptomatic primary hyperparathyroidism. J Bone Miner Res 17(Suppl 2): N98-102

15. Syed Z, Khan A (2000) Skeletal effects of primary hyperparathyroidism. Endocr Pract 6:385-88

16. Vestergaard P, Mollerup CL, Frokjaer VG, Christiansen P, Blichert-Toft M, Mosekilde L (2000) Cohort study of risk of fracture before and after surgery for primary hyperparathyroidism. BMJ 321:598-602

17. Khosla S, Melton LJ III, Wermers RA, Crowson CS, O'Fallon W, Riggs B (1999) Primary hyperparathyroidism and the risk of fracture: a population-based study. J Bone Miner Res 14:1700-1707

18. Bilezikian JP, Khan AA, Potts JT Jr (2009) Guidelines for the management of asymptomatic primary hyperparathyroidism: summary statement from the third international workshop. J Clin Endocrinol Metab 94:335-39

19. Vignali E, Viccica G, Diacinti D, Cetani F, Cianferotti L, Ambrogini E, Banti C, Del FR, Bilezikian JP, Pinchera A, Marcocci C (2009) Morphometric vertebral fractures in postmenopausal women with primary hyperparathyroidism. J Clin Endocrinol Metab 94:2306-12

20. Stein EM, Silva BC, Boutroy S, Zhou B, Wang J, Udesky J, Zhang C, McMahon DJ, Romano M, Dworakowski E, Costa AG, Cusano N, Irani D, Cremers S, Shane E, Guo XE, Bilezikian JP (2013) Primary hyperparathyroidism is associated with abnormal cortical and trabecular microstructure and reduced bone stiffness in postmenopausal women. J Bone Miner Res 28:1029-40

21. Vu TD, Wang XF, Wang Q, Cusano NE, Irani D, Silva BC, Ghasem-Zadeh A, Udesky J, Romano ME, Zebaze R, Jerums G, Boutroy S, Bilezikian JP, Seeman E (2013) New insights into the effects of primary hyperparathyroidism on the cortical and trabecular compartments of bone. Bone 55:57-63

22. Hansen S, Hauge EM, Rasmussen L, Jensen JE, Brixen K (2012) Parathyroidectomy improves bone geometry and microarchitecture in female patients with primary hyperparathyroidism: a one-year prospective controlled study using high-resolution peripheral quantitative computed tomography. J Bone Miner Res 27:1150-1158

23. Hans D, Goertzen AL, Krieg MA, Leslie WD (2011) Bone microarchitecture assessed by TBS predicts osteoporotic fractures independent of bone density: the Manitoba study. J Bone Miner Res 26:2762-69

24. Silva BC, Boutroy S, Zhang C, McMahon DJ, Zhou B, Wang J, Udesky J, Cremers S, Sarquis M, Guo XD, Hans D, Bilezikian JP (2013) Trabecular bone score (TBS)-a novel method to evaluate bone microarchitectural texture in patients with primary hyperparathyroidism. J Clin Endocrinol Metab 98:1963-70

25. Romagnoli E, Cipriani C, Nofroni I, Castro C, Angelozzi M, Scarpiello A, Pepe J, Diacinti D, Piemonte S, Carnevale V, Minisola S (2013) "Trabecular Bone Score" (TBS): an indirect measure of bone micro-architecture in postmenopausal patients with primary hyperparathyroidism. Bone 53:154-59

26. Eller-Vainicher C, Filopanti M, Palmieri S, Ulivieri FM, Morelli V, Zhukouskaya VV, Cairoli E, Pino R, Naccarato A, Verga U, Scillitani A, Beck-Peccoz P, Chiodini I (2013) Bone quality, as measured by trabecular bone score, in patients with primary hyperparathyroidism. Eur J Endocrinol 169:155-62

27. Cipriani C, Biamonte F, Costa AG, Zhang C, Biondi P, Diacinti D, Pepe J, Piemonte S, Scillitani A, Minisola S, Bilezikian JP (2015) Prevalence of kidney stones and vertebral fractures in primary hyperparathyroidism using imaging technology. J Clin Endocrinol Metab 100:1309-15

28. Odvina CV, Sakhaee K, Heller HJ, Peterson RD, Poindexter JR, Padalino PK, Pak CY (2007) Biochemical characterization of primary hyperparathyroidism with and without kidney stones. Urol Res 35:123-28

29. Corbetta S, Baccarelli A, Aroldi A, Vicentini L, Fogazzi GB, Eller-Vainicher C, Ponticelli C, Beck-Peccoz P, Spada A (2005) Risk factors associated to kidney stones in primary hyperparathyroidism. J Endocrinol Investig 28:122-28

30. Soreide JA, van Heerden JA, Grant CS, Lo CY, Ilstrup DM (1996) Characteristics of patients surgically treated for primary hyperparathyroidism with and without renal stones. Surgery 120: 1033-37

31. Frokjaer VG, Mollerup CL (2002) Primary hyperparathyroidism: renal calcium excretion in patients with and without renal stone sisease before and after parathyroidectomy. World J Surg 26:532-35

32. Silverberg SJ, Shane E, Jacobs TP, Siris ES, Gartenberg F, Seldin D, Clemens TL, Bilezikian JP (1990) Nephrolithiasis and bone involvement in primary hyperparathyroidism. Am J Med 89: 327-34

33. Pak CY, Nicar MJ, Peterson R, Zerwekh JE, Snyder W (1981) A lack of unique pathophysiologic background for nephrolithiasis of primary hyperparathyroidism. J Clin Endocrinol Metab 53:536-42

34. Muthukrishnan J, Hari Kumar KV, Jha R, Jha S, Modi KD (2008) Distal renal tubular acidosis due to primary hyperparathyroidism. Endocr Pract 14:1133-36

35. Moe OW (2006) Kidney stones: pathophysiology and medical management. Lancet 367:333-44 
36. Hedback G, Abrahamsson K, Oden A (2001) The improvement of renal concentration capacity after surgery for primary hyperparathyroidism. Eur J Clin Investig 31:1048-53

37. Yamashita H, Noguchi S, Uchino S, Watanabe S, Murakami T, Ogawa T, Masatsugu T, Takamatsu Y, Miyatake E, Yamashita H (2003) Influence of renal function on clinico-pathological features of primary hyperparathyroidism. Eur J Endocrinol 148:597-602

38. Valdemarsson S, Lindergard B, Tibblin S, Bergenfelz A (1998) Increased biochemical markers of bone formation and resorption in primary hyperparathyroidism with special reference to patients with mild disease. J Intern Med 243:115-22

39. Gianotti L, Tassone F, Cesario F, Pia A, Razzore P, Magro G, Piovesan A, Borretta G (2006) A slight decrease in renal function further impairs bone mineral density in primary hyperparathyroidism. J Clin Endocrinol Metab 91:3011-16

40. Espiritu RP, Kearns AE, Vickers KS, Grant C, Ryu E, Wermers RA (2011) Depression in primary hyperparathyroidism: prevalence and benefit of surgery. J Clin Endocrinol Metab 96: E1737-E1745

41. Wermers RA, Khosla S, Atkinson EJ, Grant CS, Hodgson SF, O'Fallon WM, Melton LJ III (1998) Survival after the diagnosis of hyperparathyroidism: a population-based study. Am J Med 104: $115-22$

42. Lundgren E, Lind L, Palmer M, Jakobsson S, Ljunghall S, Rastad J (2001) Increased cardiovascular mortality and normalized serum calcium in patients with mild hypercalcemia followed up for 25 years. Surgery 130:978-85

43. Andersson P, Rydberg E, Willenheimer R (2004) Primary hyperparathyroidism and heart disease-a review. Eur Heart J 25:177687

44. Iwata S, Walker MD, Di Tullio MR, Hyodo E, Jin Z, Liu R, Sacco RL, Homma S, Silverberg SJ (2012) Aortic valve calcification in mild primary hyperparathyroidism. J Clin Endocrinol Metab 97: $132-37$

45. Yu N, Donnan PT, Flynn RW, Murphy MJ, Smith D, Rudman A, Leese GP (2010) Increased mortality and morbidity in mild primary hyperparathyroid patients. The Parathyroid Epidemiology and Audit Research Study (PEARS). Clin Endocrinol (Oxf) 73: 30-34

46. Yu N, Leese GP, Donnan PT (2013) What predicts adverse outcomes in untreated primary hyperparathyroidism? The Parathyroid Epidemiology and Audit Research Study (PEARS). Clin Endocrinol (Oxf) 79:27-34

47. Bollerslev J, Rosen T, Mollerup CL, Nordenstrom J, Baranowski M, Franco C, Pernow Y, Isaksen GA, Godang K, Ueland T, Jansson S (2009) Effect of surgery on cardiovascular risk factors in mild primary hyperparathyroidism. J Clin Endocrinol Metab 94:2255-61

48. Walker MD, Rundek T, Homma S, DiTullio M, Iwata S, Lee JA, Choi J, Liu R, Zhang C, McMahon DJ, Sacco RL, Silverberg SJ (2012) Effect of parathyroidectomy on subclinical cardiovascular disease in mild primary hyperparathyroidism. Eur J Endocrinol $167: 277-85$

49. Persson A, Bollerslev J, Rosen T, Mollerup CL, Franco C, Isaksen GA, Ueland T, Jansson S, Caidahl K (2011) Effect of surgery on cardiac structure and function in mild primary hyperparathyroidism. Clin Endocrinol (Oxf) 74:174-80

50. Cusano NE, Maalouf NM, Wang PY, Zhang C, Cremers SC, Haney EM, Bauer DC, Orwoll ES, Bilezikian JP (2013) Normocalcemic hyperparathyroidism and hypoparathyroidism in two community-based nonreferral populations. J Clin Endocrinol Metab 98:2734-41

51. Wermers RA, Khosla S, Atkinson EJ, Achenbach SJ, Oberg AL, Grant CS, Melton LJ III (2006) Incidence of primary hyperparathyroidism in Rochester, Minnesota, 1993-2001: an update on the changing epidemiology of the disease. J Bone Miner Res 21:17177

52. Yeh MW, Ituarte PH, Zhou HC, Nishimoto S, Liu IL, Harari A, Haigh PI, Adams AL (2013) Incidence and prevalence of primary hyperparathyroidism in a racially mixed population. J Clin Endocrinol Metab 98:1122-29

53. Berger C, Almohareb O, Langsetmo L, Hanley DA, Kovacs CS, Josse RG, Adachi JD, Prior JC, Towheed T, Davison KS, Kaiser SM, Brown JP, Goltzman D (2015) Characteristics of hyperparathyroid states in the Canadian multicentre osteoporosis study (CaMos) and relationship to skeletal markers. Clin Endocrinol (Oxf) 82:359-68

54. Richert L, Trombetti A, Herrmann FR, Triponez F, Meier C, Robert JH, Rizzoli R (2009) Age and gender distribution of primary hyperparathyroidism and incidence of surgical treatment in a European country with a particularly high life expectancy. Swiss Med Wkly 139:400-404

55. Langdahl BL, Ralston SH (2012) Diagnosis and management of primary hyperparathyroidism in Europe. QJM 105:519-25

56. Yu N, Donnan PT, Murphy MJ, Leese GP (2009) Epidemiology of primary hyperparathyroidism in Tayside, Scotland, UK. Clin Endocrinol (Oxf) 71:485-93

57. Spivacow FR, Martinez C, Polonsky A (2010) Primary hyperparathyroidism: postoperative long-term evolution. Medicina (B Aires) 70:408-14

58. Eufrazino C, Veras A, Bandeira F (2013) Epidemiology of Primary Hyperparathyroidism and its Non-classical Manifestations in the City of Recife, Brazil. Clin Med Insights Endocrinol Diabetes 6:69-74. doi:10.4137/CMED.S13147. eCollection@2013:69-74

59. Bandeira F, Griz L, Caldas G, Bandeira C, Freese E (2006) From mild to severe primary hyperparathyroidism: The Brazilian experience. Arq Bras Endocrinol Metab 50:657-63

60. Zhao L, Liu JM, He XY, Zhao HY, Sun LH, Tao B, Zhang MJ, Chen X, Wang WQ, Ning G (2013) The changing clinical patterns of primary hyperparathyroidism in Chinese patients: data from 2000 to 2010 in a single clinical center. J Clin Endocrinol Metab 98:721-28

61. Bilezikian JP, Meng X, Shi Y, Silverberg SJ (2000) Primary hyperparathyroidism in women: a tale of two cities-New York and Beijing. Int J Fertil Womens Med 45:158-65

62. Shah VN, Bhadada S, Bhansali A, Behera A, Mittal BR (2014) Changes in clinical \& biochemical presentations of primary hyperparathyroidism in India over a period of 20 years. Indian J Med Res 139:694-99

63. Cipriani C, Carnevale V, Biamonte F, Piemonte S, Pepe J, Nieddu L, Bilezikian JP, Minisola S (2014) Hospital care for primary hyperparathyroidism in Italy: a 6-year register-based study. Eur J Endocrinol 171:481-87

64. Maruani G, Hertig A, Paillard M, Houillier P (2003) Normocalcemic primary hyperparathyroidism: evidence for a generalized target-tissue resistance to parathyroid hormone. J Clin Endocrinol Metab 88:4641-48

65. Tordjman KM, Greenman Y, Osher E, Shenkerman G, Stern N (2004) Characterization of normocalcemic primary hyperparathyroidism. Am J Med 117:861-63

66. Lowe H, McMahon DJ, Rubin MR, Bilezikian JP, Silverberg SJ (2007) Normocalcemic primary hyperparathyroidism: further characterization of a new clinical phenotype. J Clin Endocrinol Metab 92:3001-5

67. Marques TF, Vasconcelos R, Diniz E, Rego D, Griz L, Bandeira F (2011) Normocalcemic primary hyperparathyroidism in clinical practice: an indolent condition or a silent threat? Arq Bras Endocrinol Metab 55:314-17

68. Amaral LM, Queiroz DC, Marques TF, Mendes M, Bandeira F (2012) Normocalcemic versus Hypercalcemic Primary 
Hyperparathyroidism: More Stone than Bone? J Osteoporos 2012: 128352. doi:10.1155/2012/128352

69. Pallan S, Rahman MO, Khan AA (2012) Diagnosis and management of primary hyperparathyroidism. BMJ 344:e1013. doi:10.1136/bmj.e1013:e1013

70. Forman DT, Lorenzo L (1991) Ionized calcium: its significance and clinical usefulness. Ann Clin Lab Sci 21:297-304

71. Eastell R, Brandi ML, Costa AG, D'Amour P, Shoback DM, Thakker RV (2014) Diagnosis of asymptomatic primary hyperparathyroidism: proceedings of the Fourth International Workshop. J Clin Endocrinol Metab 99:3570-3579

72. Rejnmark L, Amstrup AK, Mollerup CL, Heickendorff L, Mosekilde L (2013) Further insights into the pathogenesis of primary hyperparathyroidism: a nested case-control study. J Clin Endocrinol Metab 98:87-96

73. Nesbit MA, Hannan FM, Howles SA, Babinsky VN, Head RA, Cranston T, Rust N, Hobbs MR, Heath H III, Thakker RV (2013) Mutations affecting G-protein subunit alpha11 in hypercalcemia and hypocalcemia. N Engl J Med 368:2476-86

74. El-Hajj Fuleihan G, Brown EM (2014) Familial hypocalciuric hypercalcemia and neonatal severe hyperparathyroidism. In: Bilezikian JP, Marcus R, Levine MA, Marcocci C, Silverberg SJ, Potts JT (eds) The parathyroids: basic and clinical concepts, 3rd edn. Academic Press, London

75. Nesbit MA, Hannan FM, Howles SA, Reed AA, Cranston T, Thakker CE, Gregory L, Rimmer AJ, Rust N, Graham U, Morrison PJ, Hunter SJ, Whyte MP, McVean G, Buck D, Thakker RV (2013) Mutations in AP2S1 cause familial hypocalciuric hypercalcemia type 3. Nat Genet 45:93-97

76. Hannan FM, Nesbit MA, Christie PT, Lissens W, Van der Schueren B, Bex M, Bouillon R, Thakker RV (2010) A homozygous inactivating calcium-sensing receptor mutation, Pro339Thr, is associated with isolated primary hyperparathyroidism: correlation between location of mutations and severity of hypercalcaemia. Clin Endocrinol (Oxf) 73:715-22

77. Rizzoli R, Green J III, Marx SJ (1985) Primary hyperparathyroidism in familial multiple endocrine neoplasia type I. Long-term follow-up of serum calcium levels after parathyroidectomy. Am J Med 78:467-74

78. Kunstman JW, Kirsch JD, Mahajan A, Udelsman R (2013) Clinical review: Parathyroid localization and implications for clinical management. J Clin Endocrinol Metab 98:902-12

79. Singer MC, Pucar D, Mathew M, Terris DJ (2013) Improved localization of sestamibi imaging at high-volume centers. Laryngoscope 123:298-301

80. Gencoglu EA, Aras M, Moray G, Aktas A (2014) The effectiveness of low-dose versus high-dose 99mTc MIBI protocols for radioguided surgery in patients with primary hyperparathyroidism. Nucl Med Commun 35:398-404

81. Philippon M, Guerin C, Taieb D, Vaillant J, Morange I, Brue T, Conte-Devolx B, Henry JF, Slotema E, Sebag F, Castinetti F (2014) Bilateral neck exploration in patients with primary hyperparathyroidism and discordant imaging results: a single-centre study. Eur J Endocrinol 170:719-25

82. Hassler S, Ben-Sellem D, Hubele F, Constantinesco A, Goetz C (2014) Dual-isotope 99mTc-MIBI/123I parathyroid scintigraphy in primary hyperparathyroidism: comparison of subtraction SPECT/CT and pinhole planar scan. Clin Nucl Med 39:32-36

83. Pata G, Casella C, Besuzio S, Mittempergher F, Salerni B (2010) Clinical appraisal of $99 \mathrm{~m}$ technetium-sestamibi SPECT/CT compared to conventional SPECT in patients with primary hyperparathyroidism and concomitant nodular goiter. Thyroid 20:1121-27

84. Hindie E, Ugur O, Fuster D, O'Doherty M, Grassetto G, Urena P, Kettle A, Gulec SA, Pons F, Rubello D (2009) 2009 EANM parathyroid guidelines. Eur J Nucl Med Mol Imaging 36:1201-16
85. Wong KK, Fig LM, Gross MD, Dwamena BA (2015) Parathyroid adenoma localization with $99 \mathrm{mTc}$-sestamibi SPECT/CT: a metaanalysis. Nucl Med Commun 36:363-75

86. Lenschow C, Gassmann P, Wenning C, Senninger N, ColomboBenkmann M (2015) Preoperative (1)(1)C-methionine PET/CT enables focused parathyroidectomy in MIBI-SPECT negative parathyroid adenoma. World J Surg 39:1750-1757

87. Cheung K, Wang TS, Farrokhyar F, Roman SA, Sosa JA (2012) A meta-analysis of preoperative localization techniques for patients with primary hyperparathyroidism. Ann Surg Oncol 19:577-83

88. Tang BN, Moreno-Reyes R, Blocklet D, Corvilain B, Cappello M, Delpierre I, Devuyst F, Van SG, Goldman S (2008) Accurate preoperative localization of pathological parathyroid glands using 11C-methionine PET/CT. Contrast Media Mol Imaging 3:157-63

89. Grayev AM, Gentry LR, Hartman MJ, Chen H, Perlman SB, Reeder SB (2012) Presurgical localization of parathyroid adenomas with magnetic resonance imaging at 3.0 T: an adjunct method to supplement traditional imaging. Ann Surg Oncol 19:981-89

90. Noureldine SI, Aygun N, Walden MJ, Hassoon A, Gujar SK, Tufano RP (2014) Multiphase computed tomography for localization of parathyroid disease in patients with primary hyperparathyroidism: How many phases do we really need? Surgery 156:1300-1306

91. Starker LF, Mahajan A, Bjorklund P, Sze G, Udelsman R, Carling $\mathrm{T}$ (2011) 4D parathyroid CT as the initial localization study for patients with de novo primary hyperparathyroidism. Ann Surg Oncol 18:1723-28

92. Witteveen JE, Kievit J, van Erkel AR, Morreau H, Romijn JA, Hamdy NA (2010) The role of selective venous sampling in the management of persistent hyperparathyroidism revisited. Eur J Endocrinol 163:945-52

93. Frokjaer VG, Mollerup CL (2002) Primary hyperparathyroidism: renal calcium excretion in patients with and without renal stone sisease before and after parathyroidectomy. World J Surg 26:532-35

94. Udelsman R, Akerstrom G, Biagini C, Duh QY, Miccoli P, Niederle B, Tonelli F (2014) The surgical management of asymptomatic primary hyperparathyroidism: proceedings of the Fourth International Workshop. J Clin Endocrinol Metab 99:3595-606

95. Agarwal G, Nanda G, Kapoor A, Singh KR, Chand G, Mishra A, Agarwal A, Verma AK, Mishra SK, Syal SK (2013) Cardiovascular dysfunction in symptomatic primary hyperparathyroidism and its reversal after curative parathyroidectomy: results of a prospective case control study. Surgery 154:1394-403

96. Rowlands C, Zyada A, Zouwail S, Joshi H, Stechman MJ, ScottCoombes DM (2013) Recurrent urolithiasis following parathyroidectomy for primary hyperparathyroidism. Ann R Coll Surg Engl 95:523-28

97. Spivacow FR, Negri AL, del Valle EE, Fradinger E, Martinez C, Polonsky A (2012) Persistence of hypercalciuria after successful surgical treatment for primary hyperparathyroidism. Int Urol Nephrol 44:857-63

98. Pashtan I, Grogan RH, Kaplan SP, Devon K, Angelos P, Liu D, Kaplan EL (2013) Primary hyperparathyroidism in adolescents: the same but different. Pediatr Surg Int 29:275-79

99. Paunovic I, Zivaljevic V, Stojanic R, Kalezic N, Kazic M, Diklic A (2013) Primary hyperparathyroidism in children and young adults:-a single institution experience. Acta Chir Belg 113:35-39

100. Denizot A, Grino M, Oliver C (2014) Surgical management of primary hyperparathyroidism in older adults. J Am Geriatr Soc 62:1759-63

101. Thomas DC, Roman SA, Sosa JA (2011) Parathyroidectomy in the elderly: analysis of 7313 patients. J Surg Res 170:240-246

102. Versnick M, Popadich A, Sidhu S, Sywak M, Robinson B, Delbridge L (2013) Minimally invasive parathyroidectomy provides a conservative surgical option for multiple endocrine neoplasia type 1-primary hyperparathyroidism. Surgery $154: 101-5$ 
103. Rajaei MH, Oltmann SC, Adkisson CD, Elfenbein DM, Chen H, Carty SE, McCoy KL (2014) Is intraoperative parathyroid hormone monitoring necessary with ipsilateral parathyroid gland visualization during anticipated unilateral exploration for primary hyperparathyroidism: a two-institution analysis of more than 2 , 000 patients. Surgery $156: 760-766$

104. Institute of Medicine of the National Academies (2011) DRI dietary reference intakes calcium vitamin D. http://books.nap. edu/openbook.php?record_id $=13050$

105. Tassone F, Gianotti L, Baffoni C, Visconti G, Pellegrino M, Cassibba S, Croce CG, Magro G, Cesario F, Attanasio R, Borretta G (2013) Vitamin D status in primary hyperparathyroidism: a Southern European perspective. Clin Endocrinol (Oxf) 79: 784-90

106. Bollerslev J, Marcocci C, Sosa M, Nordenstrom J, Bouillon R, Mosekilde L (2011) Current evidence for recommendation of surgery, medical treatment and vitamin $\mathrm{D}$ repletion in mild primary hyperparathyroidism. Eur J Endocrinol 165:851-64

107. Shah VN, Shah CS, Bhadada SK, Rao DS (2014) Effect of 25 $(\mathrm{OH}) \mathrm{D}$ replacements in patients with primary hyperparathyroidism (PHPT) and coexistent vitamin D deficiency on serum 25(OH) D, calcium and PTH levels: a meta-analysis and review of literature. Clin Endocrinol (Oxf) 80:797-803

108. Rolighed L, Rejnmark L, Sikjaer T, Heickendorff L, Vestergaard P, Mosekilde L, Christiansen P (2014) Vitamin D treatment in primary hyperparathyroidism: a randomized placebo controlled trial. J Clin Endocrinol Metab 99:1072-80

109. Stein EM, Dempster DW, Udesky J, Zhou H, Bilezikian JP, Shane E, Silverberg SJ (2011) Vitamin D deficiency influences histomorphometric features of bone in primary hyperparathyroidism. Bone 48:557-61

110. Grey A, Lucas J, Horne A, Gamble G, Davidson JS, Reid IR (2005) Vitamin D repletion in patients with primary hyperparathyroidism and coexistent vitamin D insufficiency. J Clin Endocrinol Metab 90:2122-26

111. Schmidli RS, Wilson I, Espiner EA, Richards AM, Donald RA (1990) Aminopropylidine diphosphonate (APD) in mild primary hyperparathyroidism: effect on clinical status. Clin Endocrinol (Oxf) 32:293-300

112. Reasner CA, Stone MD, Hosking DJ, Ballah A, Mundy GR (1993) Acute changes in calcium homeostasis during treatment of primary hyperparathyroidism with risedronate. J Clin Endocrinol Metab 77:1067-71

113. Rossini M, Gatti D, Isaia G, Sartori L, Braga V, Adami S (2001) Effects of oral alendronate in elderly patients with osteoporosis and mild primary hyperparathyroidism. J Bone Miner Res 16:113-19

114. Parker CR, Blackwell PJ, Fairbairn KJ, Hosking DJ (2002) Alendronate in the treatment of primary hyperparathyroid-related osteoporosis: a 2-year study. J Clin Endocrinol Metab 87:4482-89

115. Chow CC, Chan WB, Li JK, Chan NN, Chan MH, Ko GT, Lo KW, Cockram CS (2003) Oral alendronate increases bone mineral density in postmenopausal women with primary hyperparathyroidism. J Clin Endocrinol Metab 88:581-87

116. Khan AA, Bilezikian JP, Kung A, Dubois SJ, Standish TI, Syed ZA (2009) Alendronate therapy in men with primary hyperparathyroidism. Endocr Pract 15:705-13

117. Khan AA, Bilezikian JP, Kung AW, Ahmed MM, Dubois SJ, Ho AY, Schussheim D, Rubin MR, Shaikh AM, Silverberg SJ, Standish TI, Syed Z, Syed ZA (2004) Alendronate in primary hyperparathyroidism: a double-blind, randomized, placebo-controlled trial. J Clin Endocrinol Metab 89:3319-25

118. Sankaran S, Gamble G, Bolland M, Reid IR, Grey A (2010) Skeletal effects of interventions in mild primary hyperparathyroidism: a meta-analysis. J Clin Endocrinol Metab 95:1653-62
119. Marcocci C, Bollerslev J, Khan AA, Shoback DM (2014) Medical management of primary hyperparathyroidism: proceedings of the fourth International Workshop on the Management of Asymptomatic Primary Hyperparathyroidism. J Clin Endocrinol Metab 99:3607-18

120. Grey AB, Stapleton JP, Evans MC, Tatnell MA, Reid IR (1996) Effect of hormone replacement therapy on bone mineral density in postmenopausal women with mild primary hyperparathyroidism. A randomized, controlled trial. Ann Intern Med 125:360-368

121. Peacock M, Bolognese MA, Borofsky M, Scumpia S, Sterling LR, Cheng S, Shoback D (2009) Cinacalcet treatment of primary hyperparathyroidism: biochemical and bone densitometric outcomes in a five-year study. J Clin Endocrinol Metab 94:4860-4867

122. Faggiano A, Di SC, Ramundo V, Severino R, Vuolo L, Coppola A, Panico F, Savastano S, Lombardi G, Colao A, Gasperi M (2011) Cinacalcet hydrochloride in combination with alendronate normalizes hypercalcemia and improves bone mineral density in patients with primary hyperparathyroidism. Endocrine 39:283-87

123. Khan A, Bilezikian J, Bone H, Gurevich A, Lakatos P, Misiorowski W, Rozhinskaya L, Trotman ML, Toth M (2015) Cinacalcet normalizes serum calcium in a double-blind randomized, placebo-controlled study in patients with primary hyperparathyroidism with contraindications to surgery. Eur J Endocrinol 172:527-35

124. Sajid-Crockett S, Singer FR, Hershman JM (2008) Cinacalcet for the treatment of primary hyperparathyroidism. Metabolism 57:517-21

125. Iglesias P, Ais G, Gonzalez A, Tajada P, Garcia AC, Fernandez PE, Diez JJ (2008) Acute and one-year effects of cinacalcet in patients with persistent primary hyperparathyroidism after unsuccessful parathyroidectomy. Am J Med Sci 335:111-14

126. Arranz MA, Azcarate VA, Luque RM, Santana DB, Marazuela AM, Paniagua RA, Carraro R, Gomez PA (2011) Low-dose cinacalcet reduces serum calcium in patients with primary hyperparathyroidism not eligible for surgery. Endocrinol Nutr 58:24-31

127. Cetani F, Saponaro F, Banti C, Cianferotti L, Vignali E, Chiavistelli S, Viccica G, Pinchera A, Marcocci C (2012) Cinacalcet efficacy in patients with moderately severe primary hyperparathyroidism according to the European Medicine Agency prescription labeling. J Endocrinol Investig 35:655-60

128. Filopanti M, Verga U, Ermetici F, Olgiati L, Eller-Vainicher C, Corbetta S, Persani L, Beck-Peccoz P, Spada A (2012) MEN1related hyperparathyroidism: response to cinacalcet and its relationship with the calcium-sensing receptor gene variant Arg990Gly. Eur J Endocrinol 167:157-64

129. Luque-Fernandez I, Garcia-Martin A, Luque-Pazos A (2013) Experience with cinacalcet in primary hyperparathyroidism: results after 1 year of treatment. Ther Adv Endocrinol Metab 4: $77-81$

130. Saponaro F, Faggiano A, Grimaldi F, Borretta G, Brandi ML, Minisola S, Frasoldati A, Papini E, Scillitani A, Banti C, Del PM, Vescini F, Gianotti L, Cavalli L, Romagnoli E, Colao A, Cetani F, Marcocci C (2013) Cinacalcet in the management of primary hyperparathyroidism: post marketing experience of an Italian multicentre group. Clin Endocrinol (Oxf) 79:20-26

131. Truong MT, Lalakea ML, Robbins P, Friduss M (2008) Primary hyperparathyroidism in pregnancy: a case series and review. Laryngoscope 118:1966-69

132. Hirsch D, Kopel V, Nadler V, Levy S, Toledano Y, Tsvetov G (2015) Pregnancy outcomes in women with primary hyperparathyroidism. J Clin Endocrinol Metab 100(5):2115-22

133. Norman J, Politz D, Politz L (2009) Hyperparathyroidism during pregnancy and the effect of rising calcium on pregnancy loss: a call for earlier intervention. Clin Endocrinol (Oxf) 71:104-9 